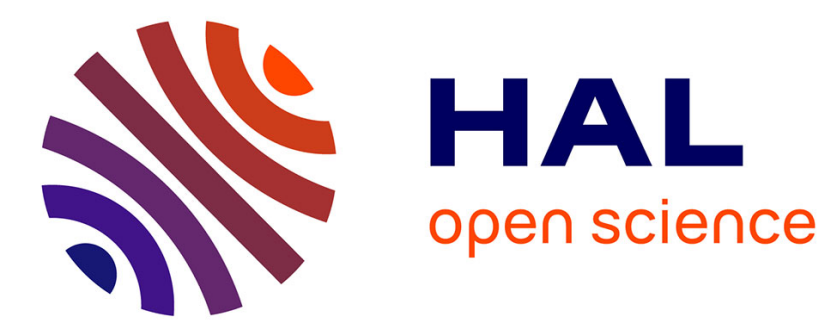

\title{
Experimental and Numerical Methods for Transition and Drag Predictions of Laminar Airfoils
}

D. Hue, O. Vermeersch, D. Bailly, V. Brunet, M. Forte

\section{To cite this version:}

D. Hue, O. Vermeersch, D. Bailly, V. Brunet, M. Forte. Experimental and Numerical Methods for Transition and Drag Predictions of Laminar Airfoils. AIAA Journal, 2015, 53 (9), p. 2694-2712. 10.2514/1.J053788 . hal-01228586

\section{HAL Id: hal-01228586 https://hal.science/hal-01228586}

Submitted on 10 Oct 2018

HAL is a multi-disciplinary open access archive for the deposit and dissemination of scientific research documents, whether they are published or not. The documents may come from teaching and research institutions in France or abroad, or from public or private research centers.
L'archive ouverte pluridisciplinaire $\mathbf{H A L}$, est destinée au dépôt et à la diffusion de documents scientifiques de niveau recherche, publiés ou non, émanant des établissements d'enseignement et de recherche français ou étrangers, des laboratoires publics ou privés. 


\title{
Experimental and Numerical Methods for Transition and Drag Predictions of Laminar Airfoils
}

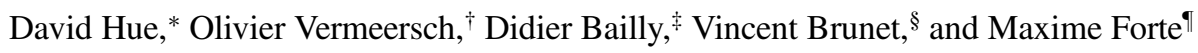 \\ ONERA-The French Aerospace Lab, 92190 Meudon, France
}

DOI: $\underline{10.2514 / 1 . J 053788}$

\begin{abstract}
The friction component is responsible for more than $40 \%$ of typical civil aircraft drag. As a consequence, the issue of laminar flow has been of prime importance in aeronautics for many years now. This article is focused on TollmienSchlichting-induced transition and drag predictions of two-dimensional laminar airfoils obtained with experimental and numerical methods. In 2012, a test campaign in the ONERA-S2MA wind tunnel, including infrared acquisitions, pressure sensors, and wake analyses, allowed substantial data to be obtained on such airfoils in transonic conditions. To complete this study, two-dimensional fluid dynamics computations have been performed, either with a Reynoldsaveraged Navier-Stokes solver using transition criteria or with a boundary-layer code combined with direct stability analysis. Furthermore, experimental (wake survey) and numerical (far-field theory) techniques allowing airfoil drag breakdown have been employed. Wind-tunnel and computational fluid dynamics transition predictions have been compared. Good agreement has been observed but the transition criteria may show some limitations in particular situations, such as long separation bubble development. The gains in lift and drag due to laminar flow have been quantified (natural vs triggered transition). Concerning drag reduction, the importance of the viscous pressure component has been highlighted. Finally, the effects of parameters such as angle of attack, Mach number, and Reynolds number on transition location and drag have been investigated.
\end{abstract}

$\begin{array}{ll} & \quad \text { Nomenclature } \\ \alpha & =\text { angle of attack } \\ C_{D f} & =\text { friction drag coefficient } \\ C_{D f f} & =\text { far-field drag coefficient } \\ C_{f x} & =\text { skin friction coefficient in the chord direction } \\ C_{D i} & =\text { lift-induced drag coefficient } \\ C_{D p} & =\text { pressure drag coefficient } \\ C_{D p r} & =\text { profile drag } \\ C_{D s p} & =\text { spurious drag coefficient } \\ C_{D t o t} & =\text { near-field total drag coefficient } \\ C_{D v} & =\text { viscous drag coefficient } \\ C_{D w} & =\text { wave drag coefficient } \\ C_{D v p} & =\text { viscous pressure drag coefficient } \\ C_{L} & =\text { lift coefficient } \\ C_{p} & =\text { pressure coefficient } \\ c & =\text { wing chord } \\ e & =\text { subscript for local state value } \\ f & =\text { frequency of boundary-layer instability } \\ M & =\text { freestream Mach number } \\ N_{T} & =\text { value of factor } N \text { at transition onset } \\ P_{i} & =\text { stagnation pressure } \\ R e & =\text { freestream Reynolds number based on the air- } \\ T_{i} & =\text { foil chord } \\ T u & =\text { stagnation temperature } \\ U, V, W & =x, y, z \text { velocity components } \\ & \end{array}$

Received 21 July 2014; revision received 10 March 2015; accepted for publication 10 March 2015; published online 29 April 2015. Copyright (C) 2015 by ONERA. Published by the American Institute of Aeronautics and Astronautics, Inc., with permission. Copies of this paper may be made for personal or internal use, on condition that the copier pay the $\$ 10.00$ per-copy fee to the Copyright Clearance Center, Inc., 222 Rosewood Drive, Danvers, MA 01923; include the code 1533-385X/15 and $\$ 10.00$ in correspondence with the CCC.

*Engineer, Civil Aircraft Unit, Applied Aerodynamics Department; david .hue@ onera.fr. Member AIAA.

${ }^{\dagger}$ Engineer, Instabilities, Transition, and Acoustics Unit, Models for Aerodynamics and Energetics Department; olivier.vermeersch@onera.fr.

"Engineer, Civil Aircraft Unit, Applied Aerodynamics Department; didier bailly@onera.fr.

${ }^{\S}$ Engineer, Civil Aircraft Unit, Applied Aerodynamics Department; vincent .brunet@onera.fr.

"Engineer, Instabilities, Transition, and Acoustics Unit, Models for Aerodynamics and Energetics Department; maxime.forte@onera.fr.

$$
\begin{array}{ll}
x, y, z & =x, y, z \text { coordinates } \\
Y+ & =\text { normalized first cell height } \\
\bar{\Lambda}_{2} & =\text { mean Pohlhausen parameter } \\
\rho & =\text { density }
\end{array}
$$

\section{Subscript}

$0 \quad=\quad$ freestream state value

\section{Introduction}

$\mathbf{L}$ AMINAR boundary layers over extended areas of an airplane surface will inevitably lead to a substantial decrease of the associated friction drag. Because this component is responsible for about $40-50 \%$ of the total drag of typical civil aircraft, the issue of laminar flow has been of prime importance for many years now (e.g., [1-3]). The design of laminar airfoils has been under consideration since the 1940s with the development of the NACA 6-series. Then, in the beginning of the 1980s, NASA used iterative numerical tools to develop a subsonic natural laminar flow (NLF) airfoil named NLF (1)-0414F [4]. This profile could exhibit extended laminar regions of $70 \%$ chord on both sides in subsonic cruise conditions. In 1984, this profile was tested in the NASA Langley low-turbulence pressure tunnel and a drag reduction of $66 \%$ was measured between the free and triggered transition configurations. The success of the low-speed NLF airfoil sparked interest in extending the design procedure to transonic regimes [5,6]. Many years later, in 2003, the Honda Jet Company developed a natural laminar flow airfoil with a $15 \%$ relative thickness for lightweight business jets [7]. This profile, named SHM1, was designed to achieve both specific subsonic climb conditions and transonic cruise conditions. Laminar properties were measured in flight using infrared imaging: It demonstrated that the laminar region extended up to $45 \%$ chord on the suction side. More recently, in the framework of the Telfona European project [ $[\underline{8}, \underline{9}]$, the Pathfinder model was designed and manufactured to evaluate the possibility of laminar flow testing in the European transonic wind tunnel. Also, still in the framework of a European project (the Joint Technology Initiatives CleanSky, Smart Fixed-Wing Aircraft), flow control technology and laminar design are currently revisited.

In this context, in 2012, Dassault Aviation and ONERA carried out studies on two-dimensional (2-D) transonic laminar airfoils in the ONERA S2MA wind tunnel. The objectives of these tests were to evaluate the laminar behavior of these airfoils in transonic conditions, to study laminar buffet and to acquire a large and detailed database for 
computational fluid dynamics (CFD) software validation. Measurement techniques included infrared (IR) acquisitions (to locate transition with temperature profiles), static and unsteady pressure sensors, and wake surveys. On the other hand, following the test matrix, a great number of CFD computations were performed, either with a Reynolds-averaged Navier-Stokes (RANS) solver using transition criteria or with a boundary-layer code combined with direct stability methods.

In this article, many experimental as well as numerical drag and transition prediction methods will be presented and compared, giving certain completeness to this publication. Nevertheless, the buffet study will not be addressed here. Furthermore, the results given in the following sections will focus on a single airfoil that was especially designed and equipped for drag and transition studies. Because all the configurations are two-dimensional, transition to turbulence will be driven by the amplification of Tollmien-Schlichting (TS) instabilities, and thus the crossflow mechanisms will not be taken into account.

At first, the present paper will describe the experimental setup, test matrix, and measurement techniques. Then, a method dedicated to extracting the drag components from the wake survey data will be presented as well as the associated results. Afterward, the numerical tools will be described: the structured grid used for the RANS computations carried out with the ONERA elsA software will be shown. Details about the transition criteria of this solver will be given. Then, the far-field drag code ONERA ffd72 as well as the boundary-layer and stability methods will be presented. Thereafter, experimental and numerical results will be compared. First, the focus will be on transition prediction. Then, the gains in lift and drag due to laminar flow will be highlighted. Finally, the effects of some parameter such as Mach and Reynolds numbers will be investigated. At last, general conclusions and perspectives will be drawn.

\section{Description of the Experiments}

\section{A. Experimental Setup and Test Matrix}

The test campaign of this study was carried out in March 2012 in the S2MA wind tunnel of ONERA (Modane-Avrieux Center). This paragraph will describe the experimental setup and the test matrix as well as the corresponding measurement techniques. One of the objectives of these experiments was to analyze the laminar property of airfoils and to quantify the impact of laminar flow on aerodynamic forces in transonic conditions.

Experiments were performed on three laminar airfoils designed and manufactured by Dassault Aviation. The models were wall-towall mounted in the S2MA test section as shown in Fig. 1. The airfoils were $900 \mathrm{~mm}$ width (in the spanwise direction) with a chord of $350 \mathrm{~mm}$. The models mounting and surface roughness have been realized to avoid premature transition. In this article, only the results obtained with the airfoil No. 2, shown in Fig. 2, will be used. This airfoil is chosen because it has allowed gathering the largest database, especially in terms of drag evaluation. The S2MA transonic test

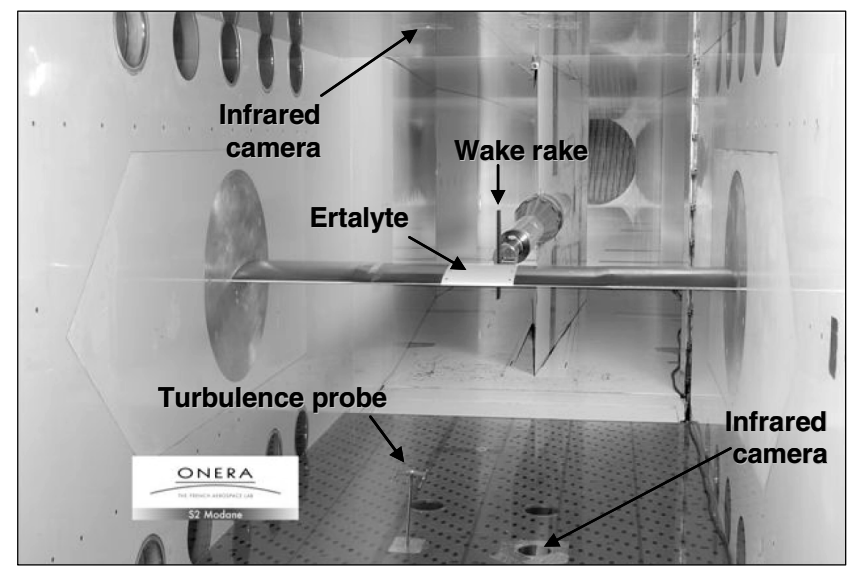

Fig. 1 S2MA test section description.

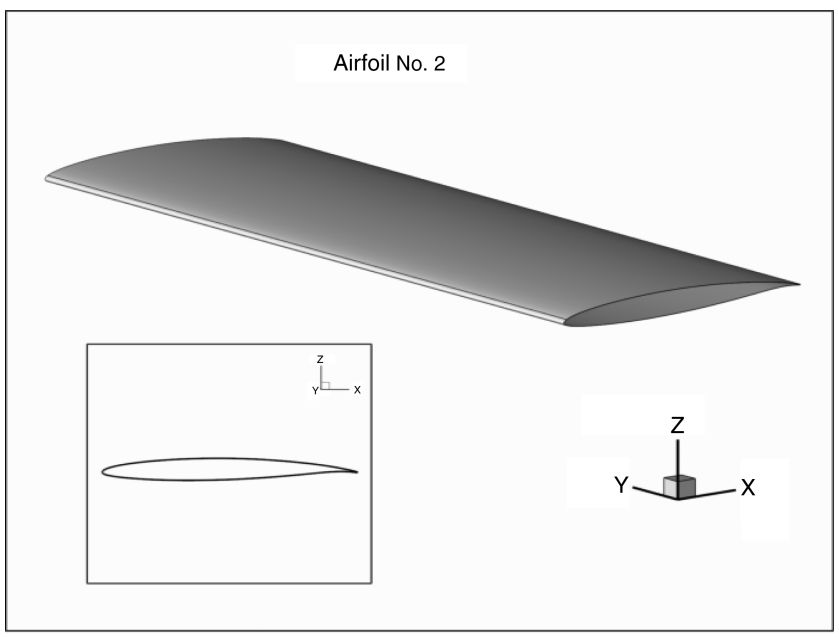

Fig. 2 Airfoil No. 2.

section is $1.760 \times 1.750 \mathrm{~m}^{2}$ and was used in solid-wall configuration to reduced noise radiated by test section walls.

During the experimental campaign, a great number of conditions were tested with a Mach number ranging from 0.3 to 0.8 . In parallel, the stagnation pressure was varied from 0.6 to 1.5 bar to study the influence of Reynolds number on airfoil properties. Table 1 shows only a part of the whole test matrix: These cases correspond to the ones that will be particularly studied in the present paper, in terms of laminar to turbulent transition and drag breakdown. To quantify the impact of laminar boundary-layer behavior on the flow and aerodynamic coefficients, the transition can be triggered or not. Transition tripping was done only on the suction side at $5 \%$ chord. It was obtained by Cadcut devices exhibiting heights similar to the boundarylayer displacement thickness $(127 \mu \mathrm{m})$.

To measure the chordwise evolution of pressure distribution, the airfoil was equipped with 62 wall static pressure taps: 41 located on the suction side and 21 on the pressure side. Pressure taps have a diameter of $0.3 \mathrm{~mm}$. A hot film probe was placed on the floor of the test section to measure velocity fluctuations. Besides, two infrared cameras measured the transition line on both sides of the airfoil. The zones aimed at being watched by infrared cameras were covered by an isolating material made of Ertalyte. Finally, to obtain the drag, a rake located one chord downstream of the airfoil trailing edge (TE) has allowed measuring of the total pressure losses in the wake. It was made of 51 total pressure probes and 7 static ones. To evaluate drag of 2-D wall-to-wall mounted models, the method of wake measurement is used to avoid the effect of wind-tunnel side walls (which would not be possible with a classical balance).

\section{B. Flow Quality Inside the Test Section}

Laminar flow measurements in wind tunnels have to face an important problem lying in the strong intensity of fluctuations inside a test section compared with free-flight conditions. As a matter of fact, external disturbances (pressure or velocity) impact and disturb boundary layers and generate instabilities through the receptivity process. The initial amplitude $A_{0}$ of these induced instabilities in the boundary layer will be all the more important if the intensity of external disturbances is high. Physically, this means that the laminar/ turbulent transition will take place closer to the leading edge for strong external disturbance levels. In transonic and supersonic wind tunnels, the noise emitted by perforated walls may become predominant (compared with velocity fluctuations) and induce an early transition. In the present test campaign, to improve wall emitted noise (i.e., reduce pressure fluctuations), the transonic test section was used in a solid-wall configuration.

The turbulence level inside the test section was measured by a hot film probe. The probe was a DANTEC dihedral sensor (DANTEC 55R31) used in constant temperature anemometry mode and thermally compensated by an anemometer DANTEC 56C. To minimize the influence of the probe on the flow, it was mounted on a profiled 
Table 1 Part of the test matrix

\begin{tabular}{lccccc}
\hline \hline & $\begin{array}{c}\text { Stagnation } \\
\text { pressure } P_{i}[\text { bar }]\end{array}$ & $\begin{array}{c}\text { Stagnation } \\
\text { temperature } T_{i}[\mathrm{~K}]\end{array}$ & $\begin{array}{c}\text { Reynolds number } \\
\operatorname{Re}\left(\times 10^{6}\right)\end{array}$ & $\begin{array}{c}\text { Transition } \\
\text { Lift range } C_{L}\end{array}$ & $\begin{array}{c}\text { Suction/Pressure sides }{ }^{\text {abb }} \\
\text { Mach number } M\end{array}$ \\
\hline 0.66 & 0.6 & 297 & 2.55 & $0.45-0.95$ & $\mathrm{Na} / \mathrm{Na}+5 \mathrm{pc} / \mathrm{Na}$ \\
0.70 & 0.6 & 297 & 2.64 & $0.48-0.91$ & $\mathrm{Na} / \mathrm{Na}+5 \mathrm{pc} / \mathrm{Na}$ \\
0.70 & 1.2 & 295 & 5.33 & $0.20-1.00$ & $\mathrm{Na} / \mathrm{Na}+5 \mathrm{pc} / \mathrm{Na}$ \\
0.73 & 1.2 & 303 & 5.32 & $0.20-1.00$ & $\mathrm{Na} / \mathrm{Na}+5 \mathrm{pc} / \mathrm{Na}$ \\
\hline \hline
\end{tabular}

${ }^{\mathrm{a}} \mathrm{Na}$ is for natural transition.

'Tripped transition at $5 \%$ chord denoted as " 5 pc."

mast located $342.5 \mathrm{~mm}$ ahead from the airfoil leading edge (LE) and $200 \mathrm{~mm}$ high. To measure signal fluctuations, a high-pass filtering with a cutoff frequency of $1 \mathrm{~Hz}$ removing the steady component was applied. The signal was then amplified with a gain equal to 500 and recorded with a sampling frequency of $100 \mathrm{kHz}$ for a period of $6 \mathrm{~s}$. After conversion of the voltage into flow momentum using King's law, power spectral densities (PSD) of the hot probe were computed. Integration of the power spectral density corresponds to the associated turbulence level:

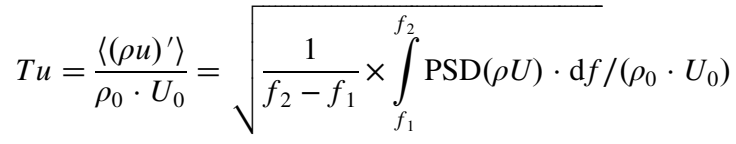

A typical spectrum is presented in Fig. 3 . To compute the turbulence level, the frequency integration range $\left[\bar{f}_{1}: f_{2}\right]$ has to be chosen carefully: The spectrum in Fig. 3 reveals that, at low frequency $(f<$ $100 \mathrm{~Hz}$ ), the PSD level is high and may not be relevant of velocity fluctuations inside the test section. The continuous component should not be taken into account when computing the turbulence level. The integration range has been chosen consequently such as $50<f<50 \mathrm{kHz}$. For this spectrum, the integration provides a turbulence level value of $T u=0.13 \%$. These measurements have been made for several wind-tunnel conditions $(0.3<M<0.8$ and $0.6<P_{i}<2$ bar) and have given turbulence levels ranging between $0.118<T u<0.166$ as shown in Fig. 4. In 2004, flow quality measurements in the S2MA wind tunnel were undertaken and both turbulence level and pressure fluctuations were measured. In Fig. 4, it can be observed that the agreement between current and previous measurements is rather good.

A classical transition prediction approach is called the $N$-factor method. Physically, the $N$ factor describes the amplification of disturbances in the boundary layer. The formulation of the $N$ factor will be given by Eq. (10) in the following section devoted to stability computations. A criterion giving the threshold value $N$ of the $N$ factor, corresponding to transition onset, has to be defined. It is the objective of Mack's semi-empirical relation [10], which establishes a

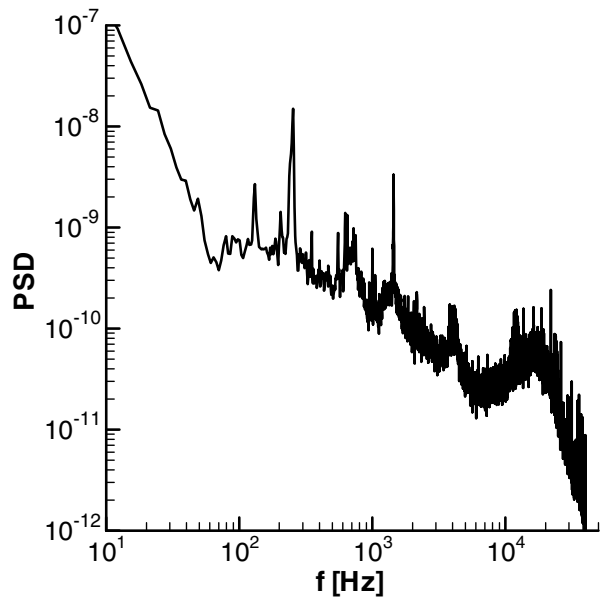

Fig. 3 Power spectral density of the flow momentum $(M=0.66$, $P_{i}=1.5$ bar). direct relation between external turbulence level and the value of the $N$ factor at transition onset:

$$
N_{T}=-8.42-2.4 \times \ln (T u)
$$

Considering the measurement of turbulence level inside the S2MA test section, Mack's formulation provides a transitional $N$ factor ranging between $6.9<N_{T}<7.8$.

A second way to quantify the flow quality uses combined infrared measurements on a reference configuration and associated stability computations. This method will be introduced and discussed in the next paragraph.

\section{Infrared Measurements}

To study the transition process taking place on both sides of the airfoil, infrared measurements were performed. IR acquisition provides the experimental transition location, and if corresponding stability computations are undertaken, a transitional $N$ factor can be accurately determined. During the campaign, IR images of both sides of the model have been systematically captured. To improve the quality of IR images, the target zone was made of an isolating insert (Ertalyte). To avoid surface discontinuity such as steps or gaps at the junction between Ertalyte and steel, the insert started from the lower side, included the leading edge, and stretched out on the upper side up to $80 \%$ chord. Even though the isolating insert undoubtedly enhanced the quality of IR images, it presents some drawbacks. Indeed, to obtain a convenient surface quality, careful polishing of the Ertalyte insert was needed. And even after this, the surface roughness was sometimes not low enough to avoid isolated turbulent wedges. Infrared images have been projected on a reference mesh with the objective of determining the transition locations on the airfoil. The infrared cameras measure the temperature of the model surface:

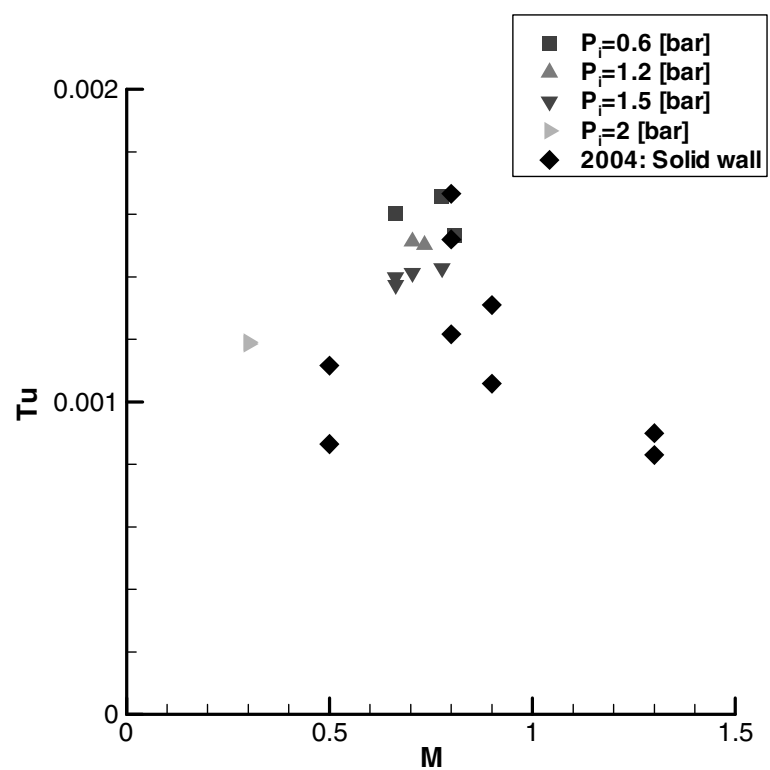

Fig. 4 Turbulence level as a function of Mach number in S2MA transonic test section; comparison between current measurements and previous estimations. 
The principle is based on the difference of the recovery factor $r$ between laminar and turbulent regimes. Thus, at the thermal equilibrium [i.e., when the temperature of the wall $T_{w}$ is equal to the adiabatic temperature (no thermal transfer)], the ratio between wall $T_{w}$ and local freestream $T_{e}$ temperatures is given by

$$
\begin{gathered}
\frac{T_{w}}{T_{e}}=\left(1+r \cdot \frac{\gamma-1}{2} \cdot M_{e}^{2}\right) \text { with }\left\{\begin{array}{l}
\text { laminar: } r_{\text {lam }}=0.85 \\
\text { turbulent: } r_{\text {turb }}=0.90
\end{array}\right. \\
\Rightarrow \Delta T=T_{w, \text { turb }}-T_{w, \text { lam }}=\left(r_{\text {turb }}-r_{\text {lam }}\right) \cdot\left(\frac{\gamma-1}{2}\right) \cdot M_{e}^{2} \cdot T_{e}
\end{gathered}
$$

An example of the infrared image can be observed in Fig. 5. Isocontours represent the wall temperature of the suction side of the model. A clear demarcation between the laminar area (dark) and turbulent one (bright) is visible. Wall temperature has been extracted along the central line $(z=0)$ and superposed to the isocontours. At $x / c \approx 62 \%$, the wall temperature dramatically increases: This is the station where first turbulent spots start appearing and will be considered in the following as the transition location. Nonetheless, physically, the transition cannot be reduced to a local point: Indeed, there is a zone where turbulent spots and laminar zones coexist, before turbulent spots grow and spray, imposing a fully turbulent boundary layer. This transitional zone, where the temperature gradient is strong, is clearly visible in Fig. 5 between 62 and $69 \%$ chord.

To determine the transitional $N$ factor of the wind tunnel, corresponding stability computations have been performed. The numerical procedure will be presented in the following dedicated section. At the experimental transition location (62\%), the maximum $N$ factor is close to $N_{T}=8$; this indirect method based on infrared measurements and stability computations provides a value slightly higher than the one directly deduced from the turbulence level measurement through Mack's relation [10]. In the future computations, the transition will be determined using $N_{T}=8$ as the threshold value.

\section{Drag Extraction from Wake Survey}

As said in the preceding part, during the test campaign, wake measurements have been performed. The present section is devoted to the drag extraction from the experimental wake survey. These

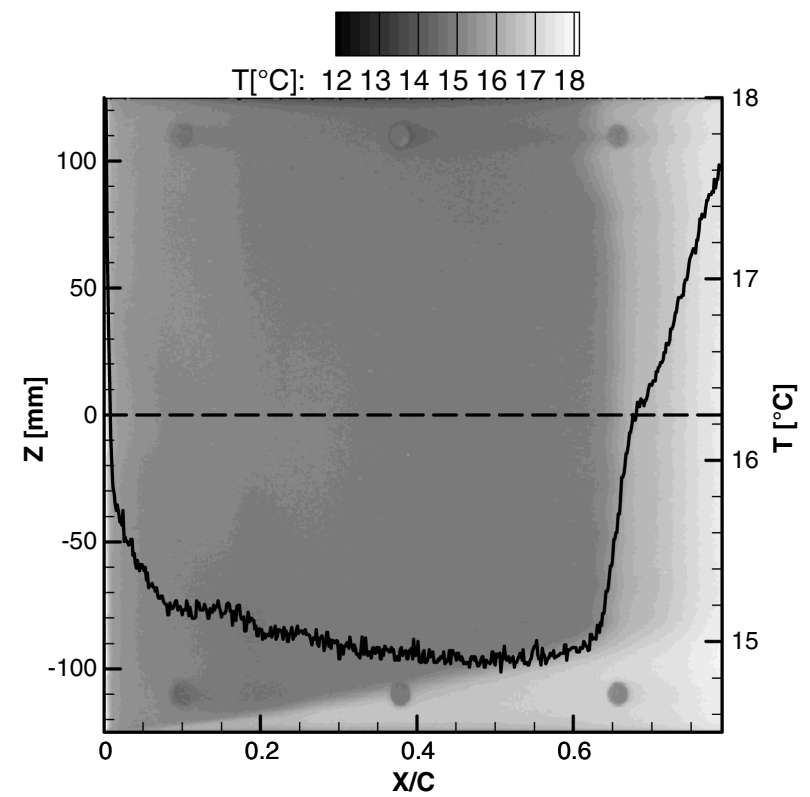

Fig. 5 Example of infrared acquisition and wall temperature evolution in chordwise direction. Solid line represents evolution of wall temperature along $x$. experimental results will be compared with numerical simulations in Sec. VI to study the influence of Mach number, Reynolds number, and transition location on drag production.

In a wind tunnel, the aerodynamic forces applied on a model can be measured by the use of a balance, in particular the total drag, but the physical breakdown cannot be obtained. On the contrary, the far-field approach provides not only the total drag but also the viscous, wave, and lift-induced terms. Lift-induced drag is linked to the appearance of wing tip vortex. The present study is restricted to a 2-D configuration: The model is between the two vertical walls of the test section, preventing from the formation of these vortices. Therefore, the lift-induced drag will not be considered. As the mechanisms of drag involve the viscous wakes, shock, and vorticity, all the necessary elements are present downstream of the model and can be measured so that each physical drag component can be quantified.

In 1925, Betz [11], and some years later, Jones [12] proposed two formulations of the profile drag based on the static and stagnation pressures. In 1956, Oswatitsch [13] gave a new formulation in function of the density, speed, and entropy. This formulation is based on the assumption of weak perturbations. In 1972, the work of Maskell [14] defined a complete drag formulation, in particular for the induced drag. During the 1990s, Brune [15] and Kusunose et al. [16-18] generalized the far-field approach for the compressible flows. In particular, Kusunose et al. [17] proposed an original breakdown of the profile drag to obtain the wave drag. Nonetheless, this method based on the vorticity can only be applied to threedimensional (3-D) flows. Meanwhile, ONERA has developed its own theoretical formulations [19], in particular, an original method of wave drag extraction that can be applied both to 2- and 3-D flows.

\section{A. Drag Breakdown Method}

As mentioned earlier, the profile drag can be calculated from the static pressure, but especially from the stagnation pressure. For each measurement point, these values provide a local value of the drag: $f(z)$. The total drag is obtained by integration of all these values. The wave drag extraction method is based on the breakdown of the profile $f(z)$ into its viscous and wave contributions. In this chapter, the theoretical profiles are noted by $\varphi(z)$, whereas the experimental ones are noted $f_{\text {exp }}(z)$.

The method uses a set $P$ of a finite number of theoretical profiles, for which the drag breakdown is known and which are similar to a given experimental profile. Because of the drag breakdown, a theoretical profile can be expressed as the sum of the viscous and wave profiles (see Fig. 6):

$$
\varphi_{i}(z)=\varphi_{i}^{v}(z)+\varphi_{i}^{w}(z) \quad i \in\{1,2, \ldots, N\}
$$

The objective is to express any experimental profile $f_{\exp }(z)$ by a linear combination of the elements of $P$, and to deduce its drag breakdown automatically by algebraic arguments:

$$
\begin{gathered}
f_{\exp }(z)=\sum_{i=1,2, \ldots, N} w_{i} \varphi_{i}(z)=\sum_{i=1, N}\left\lfloor w_{i}^{v} \varphi_{i}^{v}(z)+w_{i}^{w} \varphi_{i}^{w}(z)\right\rfloor \\
=f_{\exp }^{v}(z)+f_{\exp }^{w}(z) \\
\Rightarrow\left\{\begin{array}{l}
f_{\exp }^{v}(z)=\sum_{i=1, N} w_{i}^{v} \varphi_{i}^{v}(z) \\
f_{\exp }^{w}(z)=\sum_{i=1, N} w_{i}^{v} \varphi_{i}^{v}(z)
\end{array}\right.
\end{gathered}
$$

The first step is to define all the elements of $P$, corresponding to a set of profiles that look like the experimental data (Fig. 6). To do this, a simple analytical methodology is applied. The second part of the process consists of determining the coefficients of the linear combination. The set of profiles is supposed to span a Hilbert subspace. The determination of the coefficients is obtained by projection of the experimental profile in this subspace. The details of this drag breakdown theoretical method will be presented in a separate paper. 


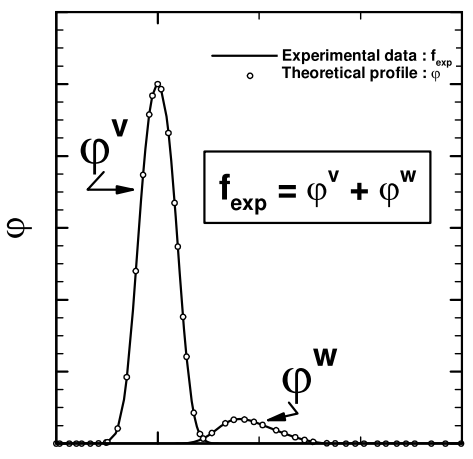

$\mathbf{Z}$

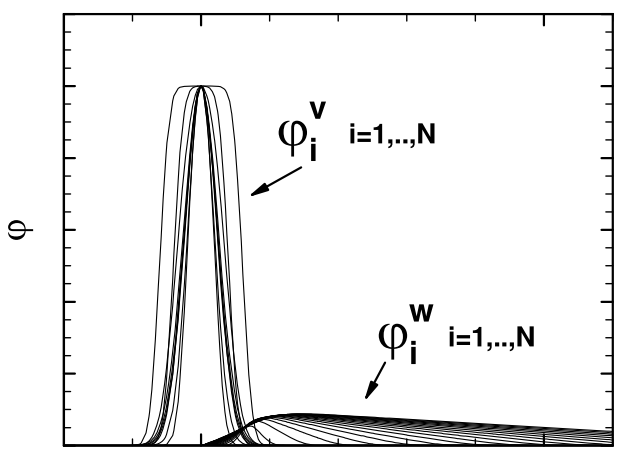

$\mathbf{Z}$

Fig. 6 Representation of experimental profile by viscous and shock functions from set of theoretical profiles ( $z$ dimensionless).

\section{B. Analysis of Stagnation Pressure Profiles}

Considering the wake survey data, the stagnation pressure is the most significant parameter because it is directly linked to the entropy production in the flow. In this section, the breakdown method is directly applied to the stagnation pressure profiles. It will be shown that very different profile types can be exploited to evaluate drag components.

From the database, three different stagnation pressure profile types can be observed (see Fig. 7):

1) The first one corresponds to low-angle-of-attack values. In these cases, the flow presents neither shock nor separation. The stagnation pressure wake is nearly symmetric and no breakdown is needed, the profile drag $C_{D p r}$ is only due to viscous drag: $C_{D p r}=C_{D v}$.

2) The second one corresponds to laminar flows with sufficiently high angles of attack. The stagnation pressure profiles exhibit two distinct parts. The first part represents the viscous wake (boundary layers) and the second is the shock wake. The breakdown is necessary: $C_{D p r}=C_{D v}+C_{D w}$. It should be noticed that the greater the angle of attack is, the more the viscous wake is asymmetrical. This is due to the flow separation just after the shock. However, even in these cases, the two parts of the wake remain clearly distinct.

3 ) In the third case, stagnation pressure profiles correspond to turbulent flows with medium and high incidences: The flow presents an asymmetric wake because of the shock and eventually separation. But, due to the turbulence, the wakes of the different physical phenomena are no longer distinct. The drag is still $C_{D p r}=C_{D v}+C_{D w}$, but the breakdown is more complicated to obtain.

It can be observed in Fig. 7 that the experimental wake profiles that have been obtained during the campaign exhibit oscillations. These oscillations might be partly due to unsteady separations occurring downstream of the shock (interaction with the rake probes). Another possible reason would be the existence of tiny vibrations affecting either the model or the measurement device. It can be noticed that the oscillation amplitudes increase with the angle of attack and seem a bit greater in natural transition conditions. To take into account this phenomenon, the experimental data are postprocessed by defining three smoothed curves. The first one takes into account all the data values (mean curve). The two other curves are defined by using maximum and minimum values. These three stagnation pressure profiles give three slightly different drag values. With these different estimations, the uncertainty due to the oscillations can be accurately quantified.

The breakdown method is particularly well suited when the viscous wake is symmetric. As a consequence, an accurate breakdown should be obtained for cases exhibiting low and medium angles of attack. For the cases with high incidences, the asymmetry of the viscous wake can be taken into account, but the oscillations clearly alter the final result accuracy.

\section{Drag Evaluation}

As said previously, during the wind-tunnel campaign, many aerodynamic conditions have been studied. This section presents only some of the results: the outcomes concerning the airfoil No. 2 at two Mach numbers $(M=0.70$ and 0.73$)$ and two types of transitions (fully natural and triggered at $5 \%$ chord on the suction side).

In Fig. 8 , the drag coefficients are given in drag counts (d.c.): 1 count $=10^{-4}$. The curves exhibit mean values and error bars (from maximum and minimum values). The uncertainty due to measurement oscillations varies with the angle of attack. Nevertheless, it can be observed that, for moderate incidences, the error bars represent about $10-20 \%$ of the absolute values. The mean coefficients are compared with the data obtained from the S2MA wake postprocessing without any smoothing. It can be observed that both evaluations give close results and that the S2MA values are in the uncertainty interval.

For the negative $\alpha$ values, the profile drag is not very sensitive to the Mach number, but it is to the transition type. It can be deduced that no shock is present in the flow and that the discrepancy between the natural/triggered curves is only due to viscous effects. The gain

Airfoil No. 2 - Pio=1.2 bar Mach=0.73
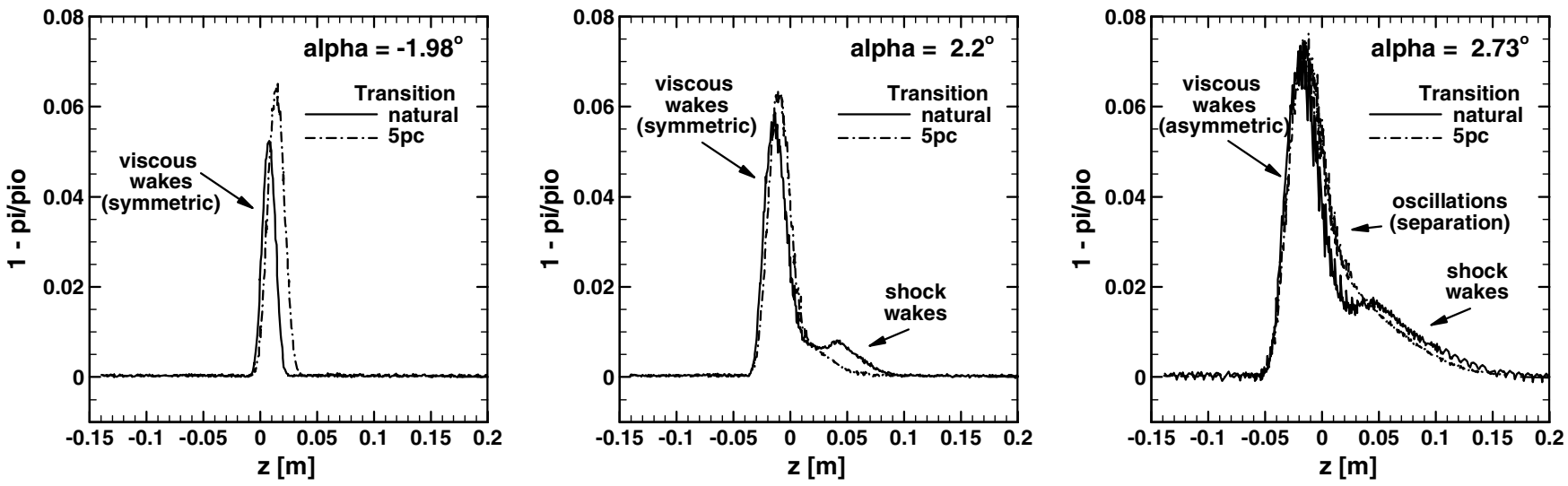

Fig. 7 Typical stagnation pressure profiles from experimental database. 


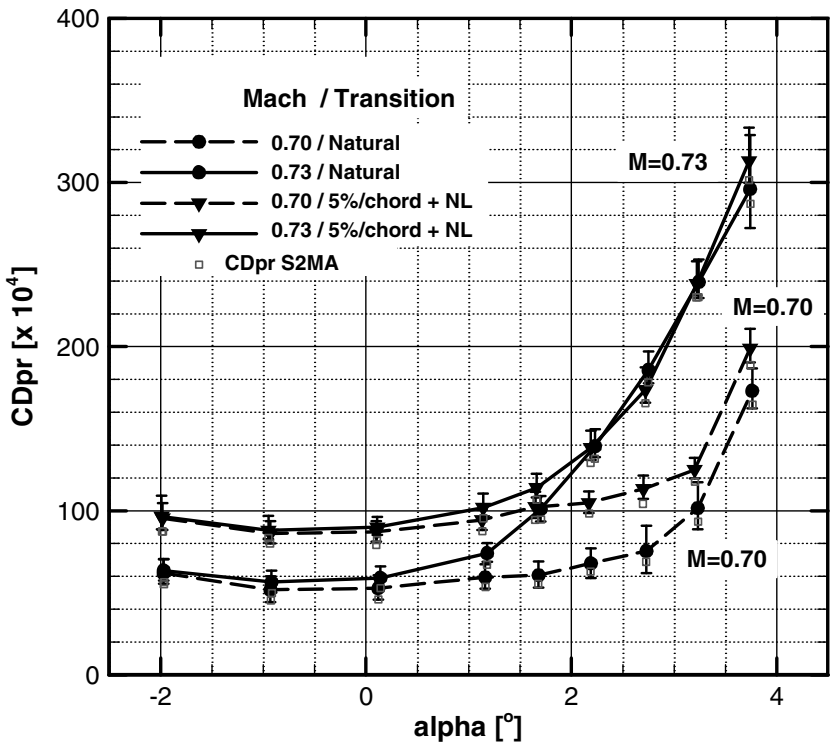

Fig. 8 Profile drag $C_{D p r}=C_{D v}+C_{D w}$; airfoil No. 2; $P_{i}=1.2$ bar.

between fully natural transition and $5 \%$ chord transition (suction side only) can be estimated as about 35-40 drag counts. For the positive $\alpha$ values, the four curves are sensitive to the transition, but also to the Mach number. This is partly due to shock occurrence on the upper side of the airfoil. At $M=0.70$, both curves (natural and 5\% transition) remain parallel up to the highest incidences. On the other hand, at $M=0.73$, the behavior that is observed is different. From $\alpha=0 \mathrm{deg}$, the natural transition drag curve rapidly converges to the line of triggered transition. For $\alpha$ values greater than $2 \mathrm{deg}$, the natural and tripped drag values are almost identical. This will be analyzed with the following breakdown.

The drag breakdown method allows obtaining the wave drag curves presented in Fig. 9. As expected, the two $C_{D w}$ curves for $M=0.70$ are almost the same. On the other hand, at $M=0.73$, the shock appears in fully natural transition conditions for $\alpha$ values close to $0 \mathrm{deg}$, whereas it seems a value of more than $1 \mathrm{deg}$ is needed with the turbulent suction side. Then, up to $\alpha=3 \mathrm{deg}$, the shock intensity of the natural transition flow is higher than the triggered transition flow. Two general outcomes can be noticed. First, at angles of attack lower than $0 \mathrm{deg}$, the wave drag should be zero, but the curve exhibits values close to 5 drag counts. This is due to the oscillations in experimental data, which accentuate a bias of the method (oscillations of $\varphi w$ in the $\varphi v$ profile axis). As a consequence, the accuracy to be considered for the wave drag evaluation is not really satisfactory in this case (within 5 counts). Second, the fact that the drag curve with natural transition rapidly converges to the one obtained with triggered transition at $M=0.73$ is not due to the wave component. It can be observed in Fig. 9 that it is the $C_{D v}$ coefficient that is responsible for this. There are likely two reasons for this behavior. First, the flow separation downstream of the shock may be greater in laminar conditions. Indeed, the shock/boundary-layer interaction with laminar bubble leads to a moderate shock strength, but with massive separation downstream of it. Then, at these strong Mach numbers and incidences, some turbulent cones appeared on the airfoil suction side during the experiments. In particular, for angles greater than 3 deg, it seems that the suction side was actually turbulent due to early unwanted transition. These experimental drag evaluations from wake survey, as well as the gains due to laminar flow, will be compared with numerical outcomes in the following sections of the article.

\section{Numerical Transition and Drag Prediction Methods}

In this section, all the numerical approaches used in this study will be shown. First, the focus will be on transition prediction methods. They will be described from the most accurate but also the most CPU time consuming to the simplest one. Secondly, the computational grid and RANS solver will be presented. Eventually, the numerical far-field drag breakdown will be briefly explained.

\section{A. Boundary-Layer and Transition Prediction Calculations}

Boundary-layer computations have been used to provide velocity profiles within the boundary-layer thickness. These profiles are the basis of the following stability computations. Boundary layers developing on both sides of the laminar airfoil were computed using the ONERA boundary-layer code 3C3D [20]. Velocity profiles were computed on 90 points in the boundary-layer thickness. Stability computations from boundary-layer velocity profiles have been made using parallel flow approximation and solving the well-known OrrSommerfeld forth-order differential equation for amplitude functions. For sake of simplicity, this equation is written in the case of incompressible flow:

$$
\begin{aligned}
& v^{I V}-2\left(\alpha^{2}+\beta^{2}\right) v^{\prime \prime}+\left(\alpha^{2}+\beta^{2}\right)^{2} v \\
& =i R\left[(\alpha U-\omega)\left(v^{\prime \prime}-\left(\alpha^{2}+\beta^{2}\right) v\right)-\alpha \frac{\mathrm{d}^{2} U}{\mathrm{~d} y^{2}} v\right]
\end{aligned}
$$

Dealing with the spatial theory, the frequency $\omega$ is real. Besides, it is assumed that there is no amplification in the spanwise direction so that $\beta$ is real too. From these statements, the stability of a disturbance
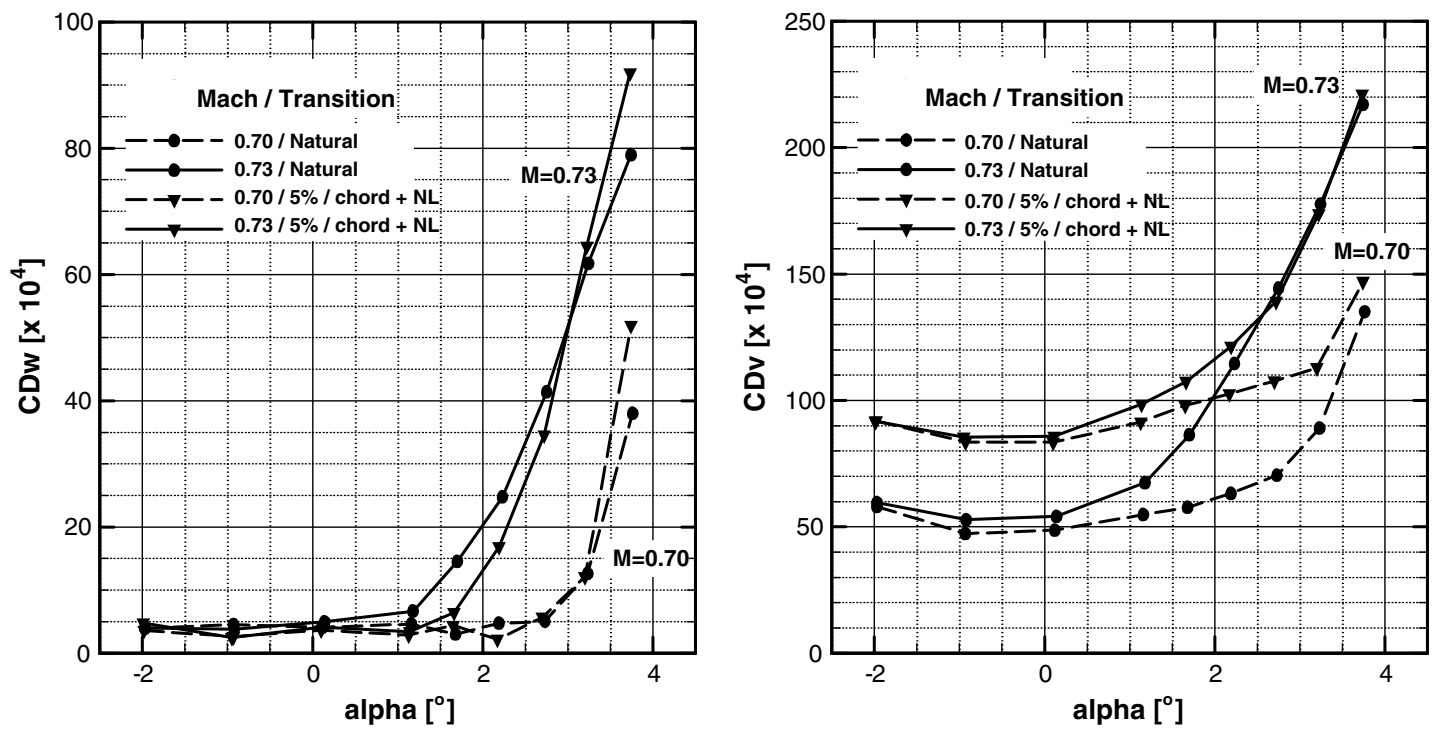

Fig. 9 Wave and viscous drag coefficients; airfoil No. $2 ; P_{i}=1.2$ bar. 


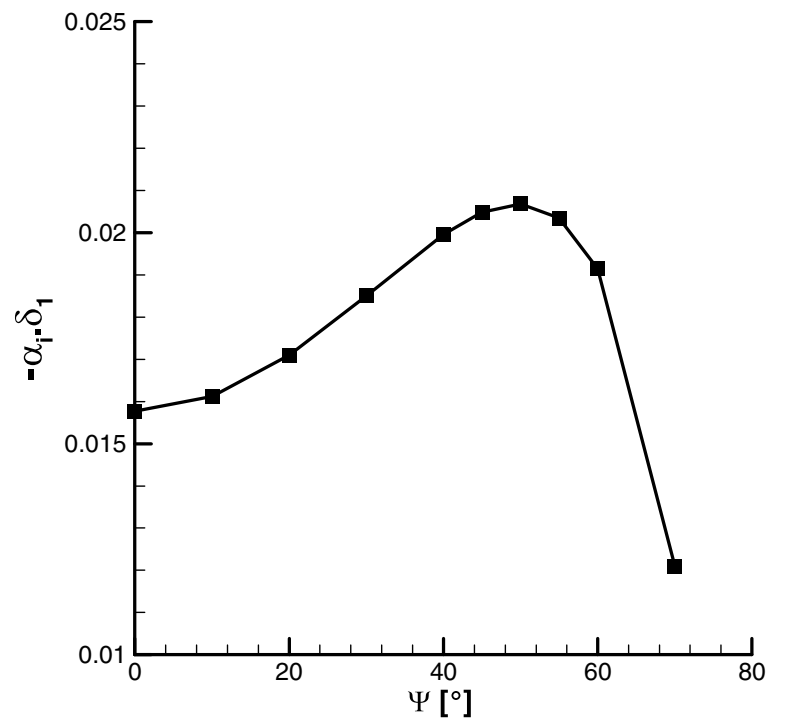

Fig. 10 Maximum growth rate as function of wave number direction at $x / c=62 \%$ (local $M=1.2$ and $R_{\delta 1}=4500$ ).

is driven by the value of the imaginary part of $\alpha=\alpha_{r}+i \alpha_{i}$, the complex wave number in the streamwise direction. It is common to introduce the angle between the external streamline and the wave number vector $\Psi$ defined as

$$
\psi=\tan ^{-1}\left(\frac{\beta}{\alpha_{r}}\right)-\theta_{0}
$$

where $\theta_{0}$ represents the angle between the streamwise direction and the external streamline.

Nontrivial solutions that exist for particular combination of $(\alpha, \Psi$, $\omega)$ are given by the so-called dispersion relation. At low speeds, in two-dimensional flows, only 2 -D waves ( $\Psi=0$, i.e., $\beta=0$ ) need to be considered, because it can be demonstrated that they are the most unstable ones (Squire's theorem). This is no longer the case when freestream Mach number increases: In transonic range, the largest amplification rate (i.e., higher $\alpha_{i}$ values) are obtained for oblique waves such as $40<\Psi<60 \mathrm{deg}$. This is clearly illustrated by the evolution of dimensionless $\alpha_{i}$ value, plotted as a function of wave number angle $\Psi$ in Fig. 10. In this case, the airfoil No. 2 is tested at $M=0.73, P_{i}=1.2$ bar, and $C_{L}=0.82$. The resolution of the OrrSommerfeld equation is performed at $x / c=62 \%$ : At this station, the local external Mach number is equal to 1.2 and the Reynolds number based on displacement thickness equals 4500 for a frequency set at $f=14 \mathrm{kHz}$. The evolution clearly shows that the highest values of $\alpha_{i}$ are obtained for $\Psi=50 \mathrm{deg}$ (corresponding to an oblique wave) rather than for $\Psi=0 \mathrm{deg}$ (corresponding to a two-dimensional wave).

The ratio between the amplitude $A$ of disturbances at a streamwise station $x$ and the initial one $x_{0}$ is given by Eq. 9 for a given frequency. In this relation, appears the $N$ factor, which describes the amplification rate of small disturbances along a path where disturbances propagate:

$$
\frac{A}{A_{0}}=\exp \left(\int_{x_{0}}^{x}-\alpha_{i}(\xi, \Psi, f) \cdot \mathrm{d} \xi\right)=e^{N}
$$

In this paper, the $N$ factor will be computed using the so-called envelope strategy. At a given streamwise position $x$, and for a fixed value of the frequency $f$, the $N$ factor is calculated such as $\alpha_{i}$ corresponds to the most unstable wave number direction:

$$
N(f)=\int_{x_{0}}^{x} \max _{\Psi}\left(-\alpha_{i}(\xi, \Psi, f)\right) \cdot \mathrm{d} \xi
$$

Linear stability theory is very effective to compute disturbance amplification within laminar boundary layers. Nonetheless, this method can be time consuming because it requires solving an eigenvalue problem at each station of disturbance path for a given couple $(\Psi, f)$. In this context, simplified transition prediction methods have been developed, in particular, transition prediction methods directly implemented in a RANS solver.

\section{B. Arnal-Habiballah-Delcourt and Gleyzes Criteria}

Transition criteria represent a compromise between accuracy and simplicity. Indeed, the fundamental mechanisms of transition processes do not appear as clearly as in stability computations. To calculate the transition location induced by TS instabilities, the Arnal-Habiballah-Delcourt (AHD) criterion has been developed [21-23]. This criterion is based on the integration line concept and was originally developed for incompressible flows over adiabatic walls. Recently, it has been extended to compressible flows. The AHD criterion uses boundary-layer stability properties and flow history. It takes into account not only the pressure distribution but also the turbulence level. It rests on the fact that transition can only be triggered in the unstable region (i.e., downstream of the neutral point $x_{\text {ins }}$, where boundary-layer instabilities are amplified). The value of momentum Reynolds number $R_{\theta \text { ins }}$ at this neutral point $x_{\text {ins }}$ is a local value depending on the incompressible shape factor $H_{i}$, such as

$$
R_{\theta \mathrm{ins}}=\exp \left(\frac{E_{\Lambda}}{H_{i}}-F_{\Lambda}\right)
$$

The incompressible shape factor $H_{i}$ is defined as the ratio between the incompressible displacement and momentum thicknesses. The calculation of these thicknesses requires accurate velocity profiles within the boundary layer, which is not always verified for RANS computations. In this context, an approximation of the incompressible shape factor as a function of the local Pohlhausen parameter is used:

$$
H_{\Lambda 2}=A_{\Lambda} \times \Lambda_{2}^{3}-B_{\Lambda} \times \Lambda_{2}^{2}+C_{\Lambda} \times \Lambda_{2}+D_{\Lambda}
$$

where $A_{\Lambda}, B_{\Lambda}, C_{\Lambda}, D_{\Lambda}, E_{\Lambda}$, and $F_{\Lambda}$ are coefficients that depend on the local Mach number [23].

If $R_{\theta}<R_{\theta \text { ins }}$ (respectively, $R_{\theta}>R_{\theta \text { ins }}$ ), the boundary-layer flow will be stable (respectively, unstable). At a given point, such as $x>x_{\text {ins }}$, stability of the boundary layer is characterized by the $R_{\theta}$ difference between the local point and the neutral one: $R_{\theta}-R_{\theta \text {,ins }}$. Influence of external pressure gradient (characterized by the mean Pohlhausen parameter $\overline{\Lambda_{2}}$ ) and influence of turbulence level on transition onset are taken into account in the definition of the transition Reynolds number $R_{\theta, T}$ :

$$
R_{\theta, T}-R_{\theta, \text { ins }}=A_{\theta} \times \exp \left(B_{\theta} \cdot \overline{\Lambda_{2, T}}\right) \times\left(\ln \left(C_{\theta} \cdot T u\right)-D_{\theta} \cdot \overline{\Lambda_{2, T}}\right)
$$

As for the incompressible shape factor expression, coefficients $\left(A_{\theta}, B_{\theta}, C_{\theta}\right.$, and $\left.D_{\theta}\right)$ depend on the local Mach number value [23]. The transitional momentum Reynolds number in Eq. (13) depends on the turbulence level $T u$ : This value has to be chosen in agreement with flow quality and reference infrared measurements. In this study, $T u=0.11 \%$, which corresponds to a $N_{T}$ factor close to 8 by Mack relationship.

To take into account highly positive pressure gradients leading to short bubble separation, the Gleyzes (GL) criterion has also been used [24]. This criterion is based on the fact that, near separation and beyond, the amplification rates of instabilities are almost independent of the frequency, but only depend on the momentum thickness Reynolds number and incompressible shape factor. In practice, the abscissa where AHD criteria is replaced by the Gleyzes one must be chosen close to the separation point (for instance, the abscissa where $H_{i}=2.8$ ). Practically, an equivalent $N$ factor $N_{\text {sep }}$ is deduced from the AHD criteria and is used as initial value for $N$ factors computed with Gleyzes criteria. 

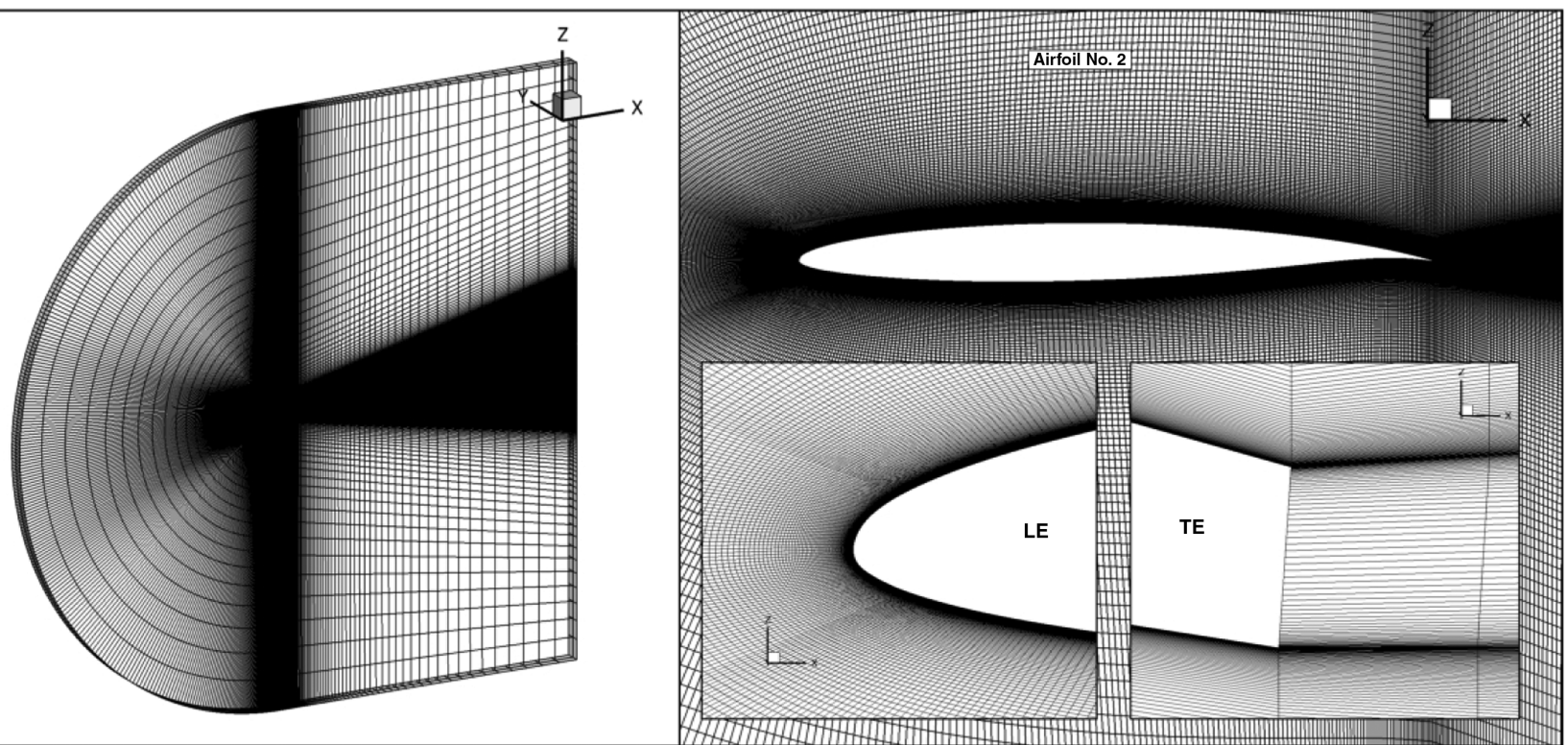

Fig. 11 RANS grid with C topology surrounding airfoil No. 2.

\section{Grid and RANS Computations}

To run the RANS solver on the airfoil described earlier, a structured grid had to be generated. This step has been completed with the ANSYS-IcemCFD HEXA software..*

The 2-D computational domain shown in Fig. 11 (left) exhibits a C topology perfectly suitable for the description of the flowfield around such an airfoil. The test section of the S2MA wind tunnel is not modeled. This domain is about 106 chords long, the origin is located at the quarter-chord, and the extent beyond this point is about 57 chords. The whole mesh is made of 215,000 elements, and as it can be noticed in Fig. 11 (right), the refinement is largely satisfactory for RANS purposes. Point distributions have been determined according to the ONERA experience in this field. The boundary-layer area presents a fine grid generated with a small stretch ratio of about 1.10. The $C$ topology ensures an accurate description of the wake area. As a validation, it appeared that the artificial drag values (see the numerical far-field theory next) produced by this grid in different aerodynamic conditions are close to zero.

Once this grid has been computed, the normalized first cell heights were checked to verify the validity of the boundary-layer discretization. According to the Reynolds number range investigated, the maximal $y+$ on the surface (trailing edge excepted) exhibited values from 0.4 to 1 , which is in compliance with the guidelines of RANS computations.

All the structured RANS computations were performed with the ONERA-elsA solver [25,26]. This software uses a cell-centered finite volume discretization on structured grids. Time integration is carried out by a backward Euler scheme with implicit LU-SSOR relaxation. Spatial discretization is realized using a second-order-accuracy central Jameson scheme [27] with artificial viscosity. Multigrid techniques can be used to accelerate the convergence. Turbulence effects have been simulated by the one-equation Spalart-Allmaras model [28]. To calculate transition, except when something else is specified, the combined AHD-GL criterion implemented in elsA is used with a threshold $N$ factor equal to 8 .

As in a 2-D lifting flow around an airfoil, it is known that velocity perturbations decrease only as the inverse of the distance to the body in the far field (whereas they decrease as the inverse of the distance squared in a three-dimensional flow) and because the grid extent is not infinitely large in this study, the "vorticity-based condition" of elsA has been used for all the computations (point-vortex correction [29]).

**Data available online at http://www.ansys.com/Products/Other +Products/ANSYS+ICEM+CFD [retrieved January 2014].
The 2-D calculations were realized in wind-tunnel aerodynamic conditions $\left(M, P_{i}, T_{i}, C_{L}\right)$. To reach a satisfactory level of convergence, the computations were continued until the fluxes were stable enough to observe a lift variation inferior to \pm 0.001 and a drag variation inferior to $1 \mathrm{drag}$ count $\left(10^{-4}\right)$ over the last thousand iterations. At least 5000 iterations using multigrid techniques (2 levels) were performed for all the calculations. When required, a target lift algorithm has enabled us to reach the lift coefficient corresponding to the experimental case under consideration.

\section{Numerical Far-Field Drag Extraction}

To compute the drag via CFD approaches, two methods can be applied: The far-field method consists of integrating values in the flow domain, whereas the near-field approach uses skin integrations only. The formulations and methods relative to the far-field theory have been presented in many former publications [30-32]. In this study, all the far-field analyses are carried out with the drag extraction software ffd72, which is based on the formulations given in [32] the references mentioned earlier.

The different drag coefficients that are used in this article are defined here:

$$
\begin{gathered}
C_{D t o t}=C_{D p}+C_{D f} \\
C_{D f f}=C_{D v}+C_{D w}+C_{D i}
\end{gathered}
$$

For understanding of the following outcomes, the viscous pressure drag $C_{D v p}$ must be defined. It is the part of the viscous drag that is not due to the friction but to displacement effect, flow separation, etc.:

$$
C_{D v}=C_{D v p}+C_{D f}
$$

The far-field formulation allows for the following near-/far-field drag balance, without $\mathrm{C}_{D i}$ in 2-D cases:

$$
C_{D p}+C_{D f}=C_{D v p}+C_{D f}+C_{D w}+C_{D i}+C_{D s p}
$$

Spurious drag $\mathrm{C}_{D s p}$ is defined as drag generated through entropy or stagnation enthalpy variations along streamlines outside physical viscous layers and shocks, and not resulting from vortex decay.

It is essential to notice that the numerical drag breakdown realized by $\mathrm{ffd} 72$ is finer than the one obtained via the wake survey. Indeed, when the latter only gives a drag breakdown into viscous and wave components, the numerical method also allows a breakdown of the viscous drag coefficient into friction and viscous pressure sources. 
Table 2 Cases presented in Sec. V.A and their main interests

\begin{tabular}{lccc}
\hline \hline Mach number $M$ & Reynolds number $R e, \times 10^{6}$ & Lift coefficient $C_{L}$ & Main interests \\
\hline 0.66 & 2.55 & 0.7 & Low Mach and Reynolds numbers/weak recompression \\
0.70 & 2.64 & 0.9 & $\begin{array}{c}\text { Stronger Mach number and lift/presence of shock } \\
0.70\end{array}$ \\
0.33 & $0.5+0.8$ & $\begin{array}{c}\text { Case of refence + case with oscillations in } C p \text { distribution } \\
\text { leading to transition criteria inaccuracy }\end{array}$ \\
0.73 & 5.32 & 0.8 & $\begin{array}{c}\text { Strong Mach and Reynolds numbers/case producing a laminar } \\
\text { bubble with flow separation at shock foot }\end{array}$ \\
\hline \hline
\end{tabular}

\section{Transition Predictions and Gains Due to Laminar Flow}

In this part, both experimental and numerical results are presented. Two main issues will be discussed. First, the aspects concerning transition prediction will be investigated. The wind-tunnel and CFD data will be compared. In a perspective of validation, the limitations of methods will be addressed. Secondly, the gains in lift and drag due to laminar flow will be highlighted.

\section{A. Transition Prediction}

The purpose of this section is to compare the different methods that have been employed to predict the transition location: experimental infrared acquisitions, RANS solver with transition criteria, and boundary-layer code with stability analyses. Stability analyses have been conducted on the flow provided by experimental wall static pressure measurements. Because many results have been collected (large test matrix and numerous associated computations), only some of them are presented here. Among the cases shown in this section, several of them exhibit good experimental/numerical agreement, whereas others show method limitations. Because the purpose is to determine the transition location, the five chosen cases have natural transition on both sides of the airfoil (no triggering). All these cases and their main interests are gathered in Table 2 .

\section{1. $M=0.66, P_{i}=0.6$ bar, $C_{L}=0.7$}

Both experimental and numerical investigations have been realized in the following conditions: $M=0.66, P_{i}=0.6$ bar, and $T_{i}=297 \mathrm{~K}$, leading to a chord Reynolds number of 2.55 million. The lift coefficient of the experimental run is 0.714 and the lift coefficient of the associated elsA computation is equal to 0.717

As can be noticed in Fig. 12 (left), the agreement in terms of pressure distributions between the CFD and S2MA data is quite satisfactory. The numerical transition locations on both sides can be estimated from Fig. 12. They are close to $65 \%$ chord. The elsA
Table 3 Experimental and numerical transition locations $M=0.66, P_{i}=0.6 \mathrm{bar}, C_{L}=0.7$

\begin{tabular}{lccc}
\hline \hline & \multicolumn{2}{c}{$\begin{array}{c}\text { Pressure side, } \\
\text { \% chord }\end{array}$} & $\begin{array}{c}\text { Suction side, } \\
\% \text { chord }\end{array}$ \\
\hline Experiment & 0.714 & 66 & 62 \\
elsA (AHD-GL) & 0.717 & 68 & 64 \\
Exact stability & 0.714 & Separation at $x / c=62 \%$ & $61(f=14 \mathrm{kHz})$ \\
\hline \hline
\end{tabular}

variable "intermittency" (Fig. 12, right) precisely indicates the position obtained by the criteria.

In Table 3, the numerical transition locations are compared with the experimental data provided by the infrared measurements. The infrared visualization for the suction side can be seen in Fig. 5. With the temperature distributions, it is possible to measure transition location corresponding to the station where wall temperature significantly increases: In this case, transition occurs at $x / c=66 \%$ for the pressure side and $62 \%$ on the suction side. As a consequence, the experimental/elsA agreement is particularly good in these conditions (only 2\% chord of difference for both sides). This comparison in soft conditions represents a first validation of the transition prediction obtained with the elsA AHD-GL criteria.

Concerning the exact stability approach, the evolution of $N$ factors on both sides of the airfoil is shown in Fig. 13. Additionally, to analyze the influence of external flow on the growth of disturbances, the longitudinal velocity evolution has been plotted. In a classical way, TS instabilities are amplified in the region corresponding to decelerated external flow. This can be particularly observed on the pressure side (Fig. 13a). The external flow is strongly accelerated from the leading edge up to $30 \%$ chord: This prevents from the appearance and amplification of instabilities in the first region. The critical abscissa (i.e., the station from which the boundary layer becomes unstable) is located at $x / c=30 \%$. In comparison, the AHD criterion provides a critical point around $31 \%$ of chord (see Table 4 ).
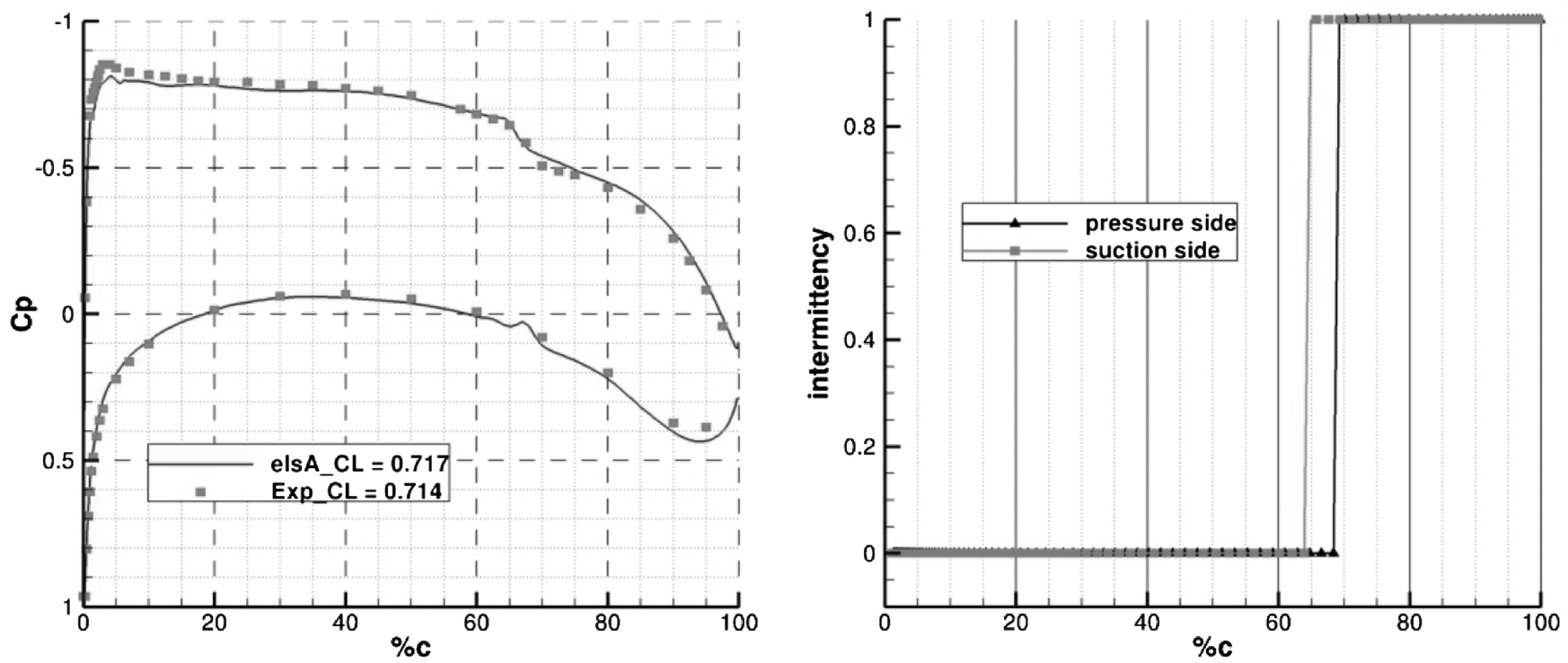

Fig. 12 Pressure distributions (right) and elsA transition locations (left); $M=0.66, P_{i}=0.6 \mathrm{bar}, C_{L}=0.7$; natural transition. 


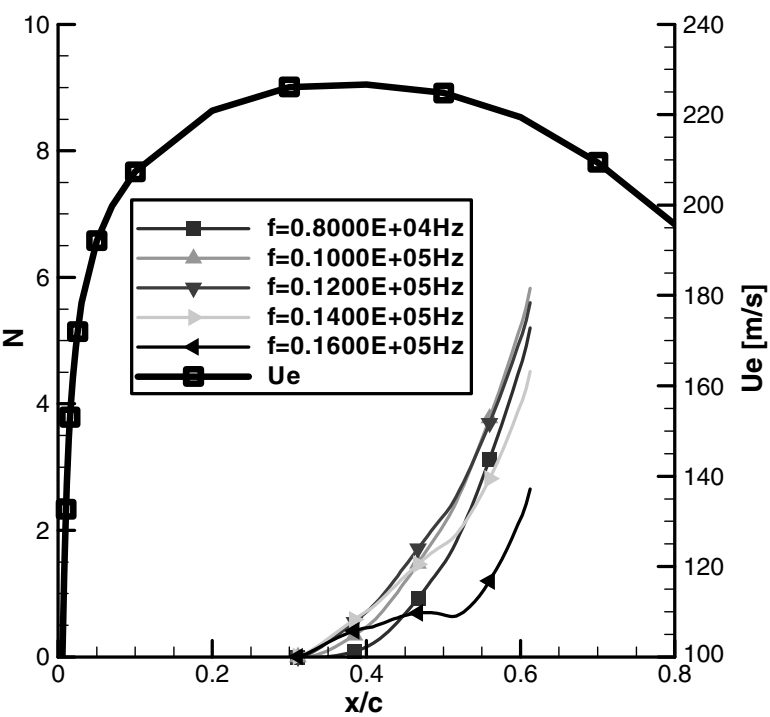

a) Pressure side

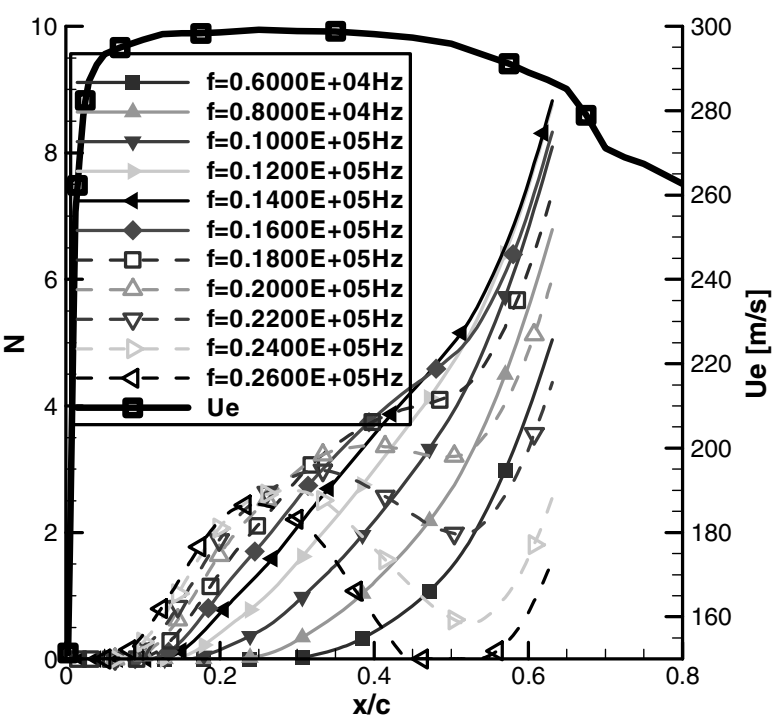

b) Suction side

Fig. 13 Stability computations; $M=0.66, P_{i}=0.6 \mathrm{bar}$, and $C_{L}=0.7$.

Further, the pressure gradient is more and more important, leading to a strong amplification of TS waves, with a most unstable frequency of about $f=10 \mathrm{kHz}$. Before separation, the $N$-factor value is equal to 6 .

On the suction side (Fig. 13b), the accelerated zone is very narrow, restricted to the first percents of chord, followed by a nearly zero pressure gradient. Thus, TS amplification starts at around 5\% of chord. Exact stability computations show that the first amplified wave has a frequency of $26 \mathrm{kHz}$ and appears at $6.3 \%$ of chord; AHD criterion provides a critical abscissa at $4 \%$ of chord. Still dealing with the suction side, high frequencies are the first to be amplified. The transitional $N$ factor $N_{T}=8$ provided by exact stability is reached at $61 \%$ chord, in close agreement with measurement and RANS computations. The disturbance responsible for transition has a frequency of $f=14 \mathrm{kHz}$.

\section{2. $M=0.70, P_{i}=0.6$ bar, $C_{L}=0.9$}

The aerodynamic conditions for both wind-tunnel and CFD approaches are the following: stronger Mach number $M=0.70$, $P_{i}=0.6$ bar, and $T_{i}=297 \mathrm{~K}$ leading to a chord Reynolds number of 2.64 million. The lift coefficient for both methods is strong (close to 0.91 ) and the transition is not imposed. Figure 14 shows the experimental and numerical pressure distributions in iso- $C_{L}$ conditions. The agreement is quite satisfactory, especially for the shock position. In Table $\underline{5}$, the elsA transition locations are compared with the experimental measurements provided by infrared images. The IR data as well as the evolution of temperature profile are shown in Fig. 15 for the suction side. The temperature profile seems to indicate that transition occurs at $x_{T} / c \approx 48 \%$, and contrary to the former case, a shock is clearly visible at $x / c \approx 50 \%$. For elsA, the transition on the suction side also occurs close to $50 \%$. The agreement between the numerical and experimental predictions is very good and demonstrates the reliability of the elsA approach in such conditions (transition at shock foot). Concerning the pressure side, the transition location given by the criteria is identical to the one extracted from the IR images. These outcomes have been again confirmed by the associated stability analyses. As for the previous case, on the pressure side, the adverse pressure gradient is important in such a way that the

Table 4 Numerical critical abscissa, $x_{\text {ins }} / c$; $M=0.66, P_{i}=0.6 \mathrm{bar}, C_{L}=0.7$

\begin{tabular}{lcc}
\hline \hline & Pressure side, $\%$ & Suction side, $\%$ \\
\hline AHD criteria & 31 & 4.12 \\
Exact stability & 30 & 6.3 \\
\hline \hline
\end{tabular}

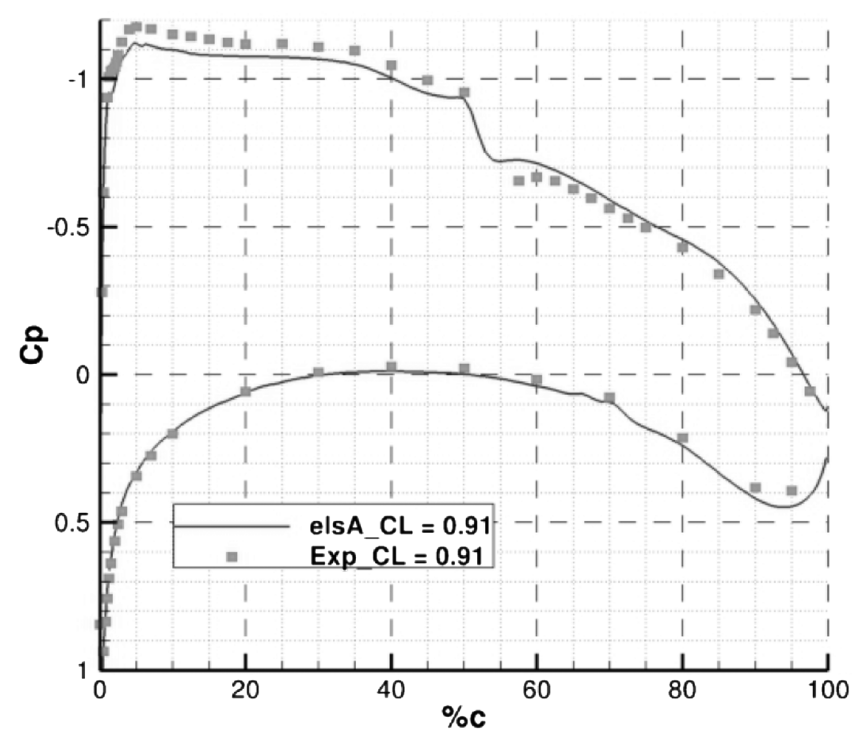

Fig. 14 Pressure distributions; $M=0.70, P_{i}=0.6 \mathrm{bar}, C_{L}=0.91$; natural transition.

boundary-layer code predicts separation. On the suction side, disturbances start being amplified at $10 \%$ of chord and the transitional $N$ factor is reached at $48 \%$ chord for $f=18 \mathrm{kHz}$.

3. $M=0.70, P_{i}=1.2$ bar, $C_{L}=0.5$ and $C_{L}=0.8$

In these cases, the Mach number is still 0.70 but the stagnation pressure is doubled, which leads to a Reynolds number of 5.33 million. Two lift levels are presented: the first one is moderate, whereas the second one corresponds to a particular situation in which the pressure distribution exhibits a plateau in the first half of the suction side.

The pressure coefficient distribution of the case exhibiting moderate lift level is shown in Fig. 16a. It seems that the computation

Table 5 Experimental and numerical transition locations; $M=0.70, P_{i}=0.6$ bar, $C_{L}=0.91$

\begin{tabular}{lccc}
\hline \hline & \multicolumn{1}{c}{$\begin{array}{c}\text { Pressure side, } \\
\% \text { chord }\end{array}$} & $\begin{array}{c}\text { Suction side, } \\
\% \text { chord }\end{array}$ \\
\hline Experiment & 0.91 & 68 & 50 \\
elsA (AHD-GL) & 0.91 & 68 & 48 \\
Exact Stability & 0.91 & Separation at $x_{s} / c=66 \%$ & $48(f=18 \mathrm{kHz})$ \\
\hline \hline
\end{tabular}


gives lower $C_{p}$ than the experiments in the first half of the suction side and greater $C_{p}$ in the second half. This behavior was also observed for the previous run $\left(M=0.7, P_{i}=0.6\right.$ bar, $\left.C_{L}=0.9\right)$. Moreover, in this case, the RANS solver predicts a shock location several percents downstream of the experimental measurements on the suction side. Regarding transition prediction, both elsA and IR results are given in Table 6 . The laminar flow extent is very large in these conditions.

For the second case of this subsection, the lift coefficient is equal to 0.8 (see Fig. 16b). In these very specific conditions (negligible pressure gradient on all of the first half of the suction side), the numerical convergence is still perfectly satisfactory, but the elsA pressure distribution that is obtained shows a zone of oscillations instead of the experimental $C_{p}$ plateau. Several compressions and expansions are observed, the Mach number being really close to one in this zone above the airfoil. This particular situation (which disappears with slightly lower or higher $C_{L}$ or $M$ ) disturbs the transition prediction. As a consequence, the elsA transition location on the suction side is clearly not in agreement with the experiments

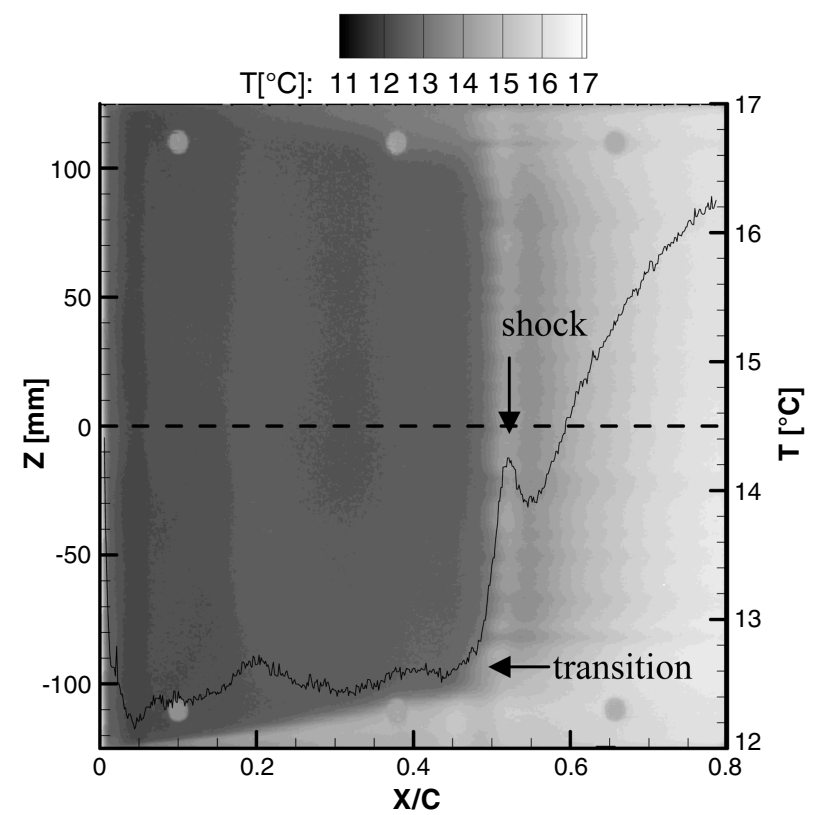

Fig. 15 Infrared thermography and wall temperature evolution of the suction side; $M=0.70, P_{i}=0.6 \mathrm{bar}, C_{L}=0.91$.

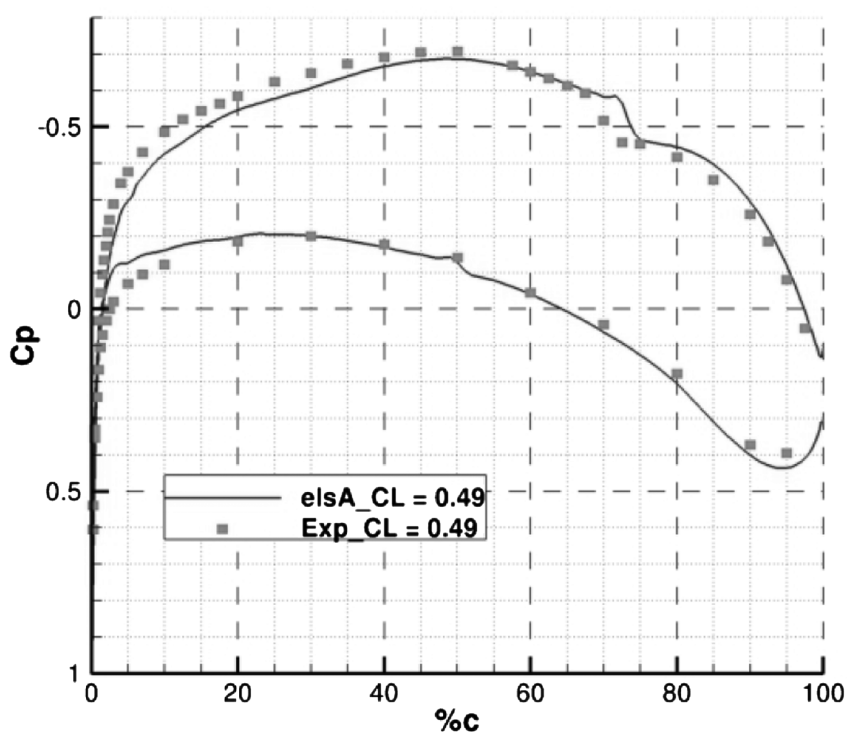

Table 6 Experimental and numerical transition locations; $M=0.70, P_{i}=1.2 \mathrm{bar}, C_{L}=0.5$

\begin{tabular}{lccc}
\hline \hline & $C_{L}$ & Pressure side, \% chord & Suction side, \% chord \\
\hline Experiment & 0.49 & 55 & 75 \\
elsA (AHD-GL) & 0.49 & 51 & 72 \\
\hline \hline
\end{tabular}

Table 7 Experimental and numerical transition locations; $M=0.70, P_{i}=1.2 \mathrm{bar}, C_{L}=0.8$

\begin{tabular}{lccc}
\hline \hline & $C_{L}$ & Pressure side, \% chord & Suction side, \% chord \\
\hline Experiment & 0.81 & 65 & 55 \\
elsA (AHD-GL) & 0.81 & 67 & 18 \\
Exact stability & 0.81 & $62(f=14 \mathrm{kHz})$ & $51(f=20 \mathrm{kHz})$ \\
\hline \hline
\end{tabular}

(see Table 7). This case illustrates a limitation of the approach based on the RAN̄S solver.

4. $M=0.74, P_{i}=1.2$ bar, $C_{L}=0.8$

The last run exhibits strong Mach and Reynolds numbers ( 0.73 and 5.32 million, respectively) and a high lift level close to 0.8 . Because it produces a laminar bubble and flow separation at the shock foot, this case is particularly interesting.

Pressure distributions presented in Fig. 17a show a very good overall agreement between numerical and experimental data. However, a significant discrepancy appears on the suction side $15 \%$ chord upstream from the shock position. A priori, because the flow is continuously accelerated, the boundary layer remains laminar, leading to a laminar bubble that provokes flow separation at the shock foot. The RANS computation does not reproduce this phenomenon accurately. Figure $17 \mathrm{~b}$, which shows the numerical skin friction coefficient, is added as an additional illustration of these comments. In a narrow zone, a few percents upstream of the shock, the skin friction becomes negative, and this highlights a separation phenomenon. This is confirmed by IR images and stability analysis illustrated in Figs. 18a and 18b, respectively: Due to a constant acceleration from the leading edge, $N$ factors remain very low $(N<2)$, meaning that the boundary layer will stay laminar up to the shock. The laminar boundary layer will first separates due to the shock and form a laminar transitional bubble. Transition will occur inside this bubble, provoking a boundary-layer reattachment. This is illustrated by the unusual evolution of wall temperature deduced from IR images and shown in Fig. 18a. The transition locations given in Table $\underline{8}$ show that

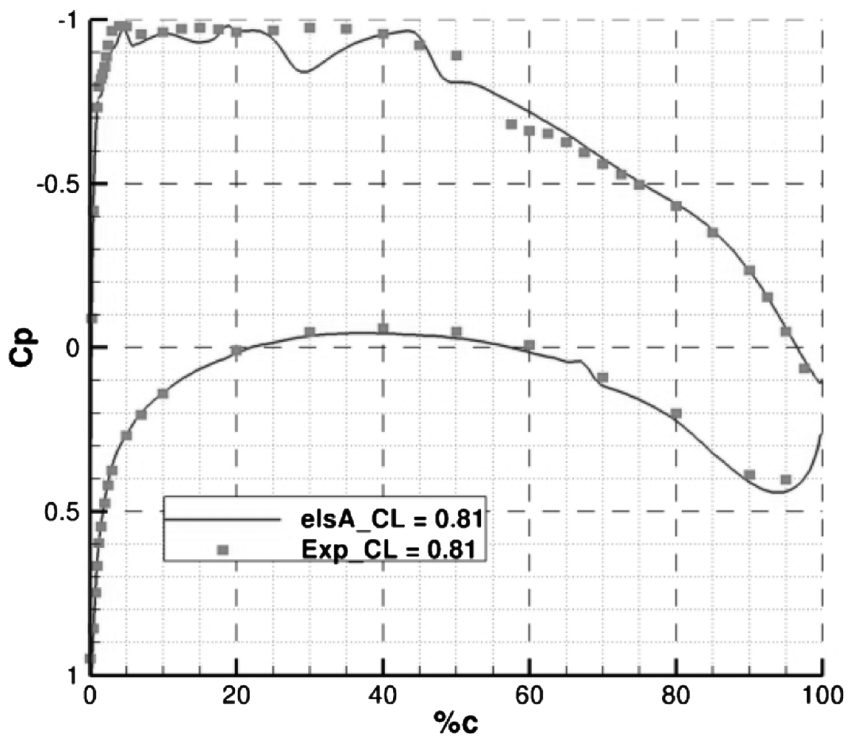

b) $C_{L}=0.8$

a) $C_{L}=0.5$

Fig. 16 Pressure distributions; $M=0.70, P_{i}=1.2 \mathrm{bar}, C_{L}=0.5$ and 0.8 ; natural transition. 


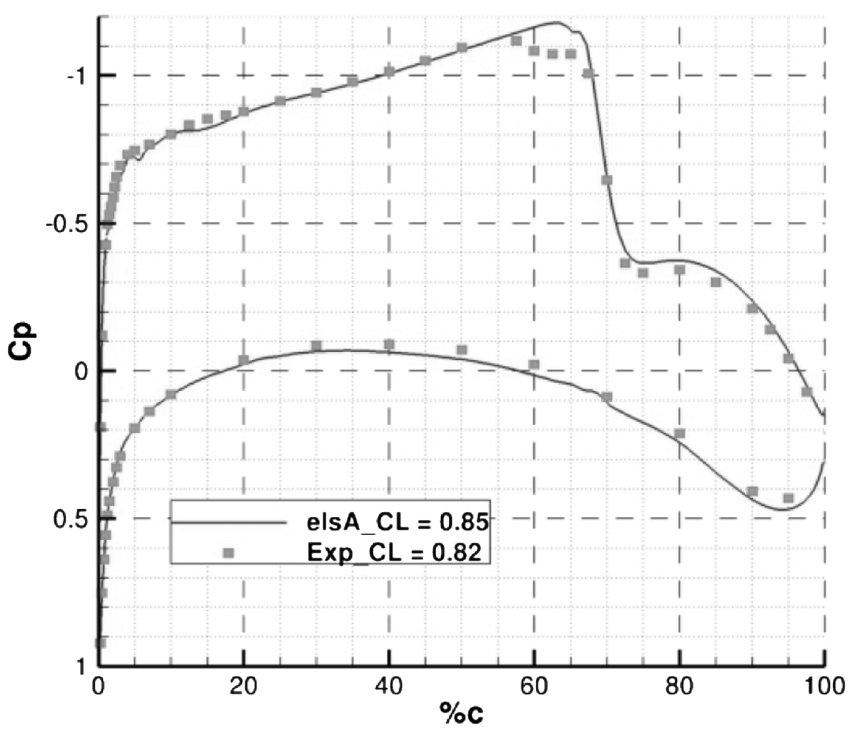

a) Pressure distribution

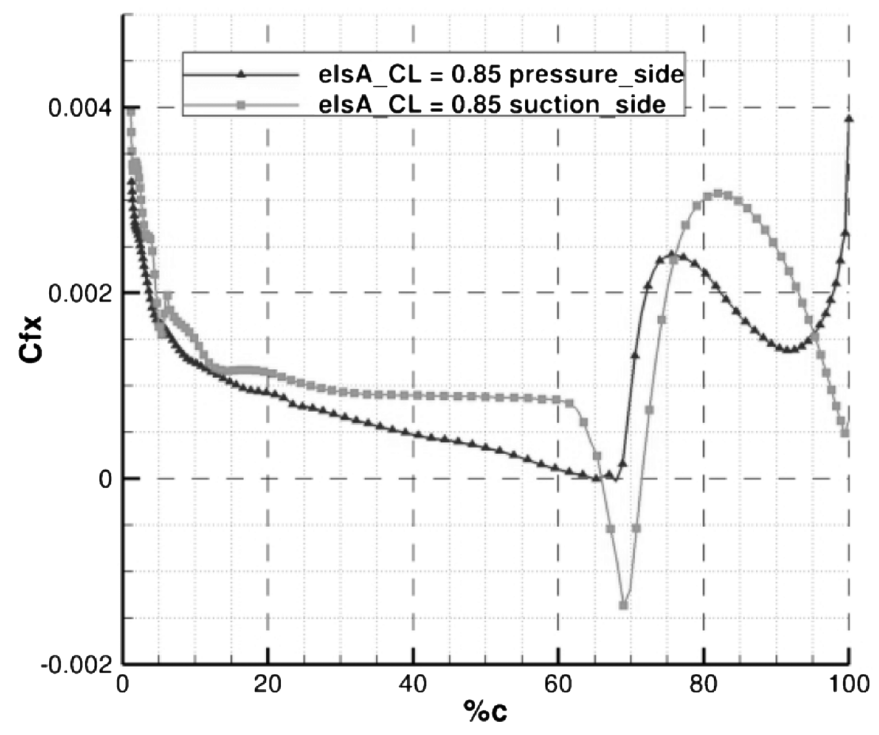

b) Skin friction distribution

Fig. 17 Pressure and friction distributions; $M=0.73, P_{i}=1.2 \mathrm{bar}, C_{L}=0.8$; natural transition.

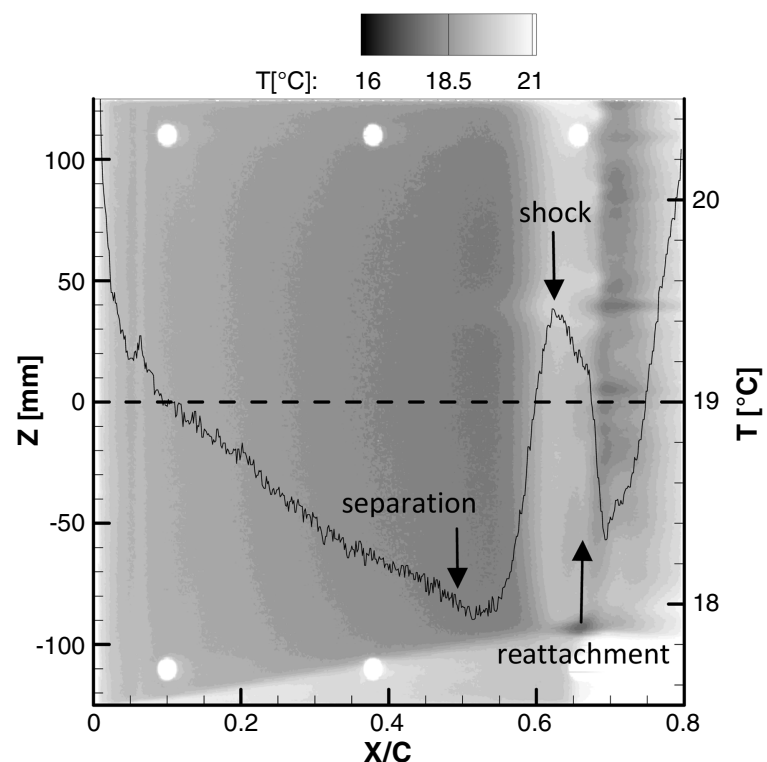

a) Infra-red thermography and wall temperature evolution

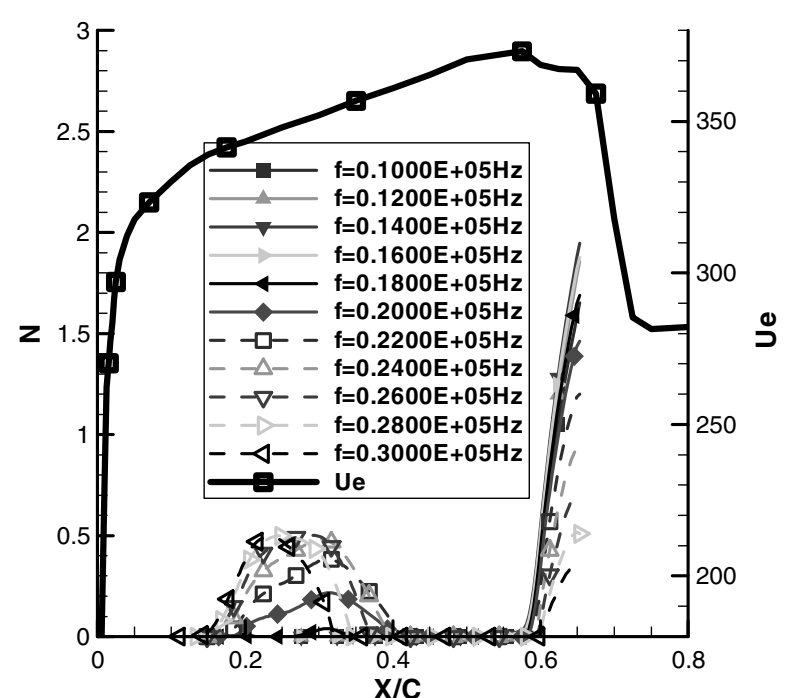

b) Stability computations

Fig. 18 Suction side; $M=0.73, P_{i}=1.2 \mathrm{bar}, C_{L}=0.8$.

the elsA prediction on the suction side is satisfactory, despite the fact that the physics is not perfectly captured. Concerning the pressure side, the difference of $6 \%$ chord in transition location between the elsA computation and measurements can probably be explained by the fact that the CFD lift coefficient is stronger than the experimental one, which is favorable for the boundary-layer stability on this side.

Considering the laminar bubble, it can be observed that its length is significant (about 15\% chord). It is specific of an interaction of a strong shock wave with a laminar boundary layer. Indeed, in Fig. 19, the experimental pressure coefficient evolution for the laminar boundary layer (current case) has been compared with the one obtained for the same flow conditions but with a 5\% tripped transition. For the turbulent boundary layer, the shock appears at $58 \%$ chord instead of $68 \%$ for the laminar case, and the corresponding $C_{p}$ distribution does not exhibit the particular cup point trend.

\section{B. Laminar Design Effects on Lift and Drag Coefficients}

This section aims at highlighting the gains observed in lift and drag coefficients due to laminar flow. To do so, two types of cases are compared: The first ones exhibit natural transition on both sides of the airfoil, whereas the second ones have been realized with a triggered transition at 5\% chord on the suction side (no triggering on pressure side).

As will be observed in the following figures, the numerical data are preferred to the experimental results in the rest of the article. There are two arguments for such a choice. First, in this study, some discrepancies appeared between the CFD and wind-tunnel drag estimations.

Table 8 Experimental and numerical transition locations; $M=0.73, P_{i}=1.2 \mathrm{bar}, C_{L}=0.8$

\begin{tabular}{lccc}
\hline \hline & $C_{L}$ & $\begin{array}{c}\text { Pressure side, } \\
\text { \% chord }\end{array}$ & $\begin{array}{c}\text { Suction side, } \\
\text { \% chord }\end{array}$ \\
\hline Experiment & 0.82 & 59 & 67 \\
elsA (AHD-GL) & 0.85 & 65 & 65 \\
Exact stability & 0.82 & $59(f=14 \mathrm{kHz})$ & Laminar up to \\
& & & shock at $x / c=65 \%$ \\
\hline \hline
\end{tabular}




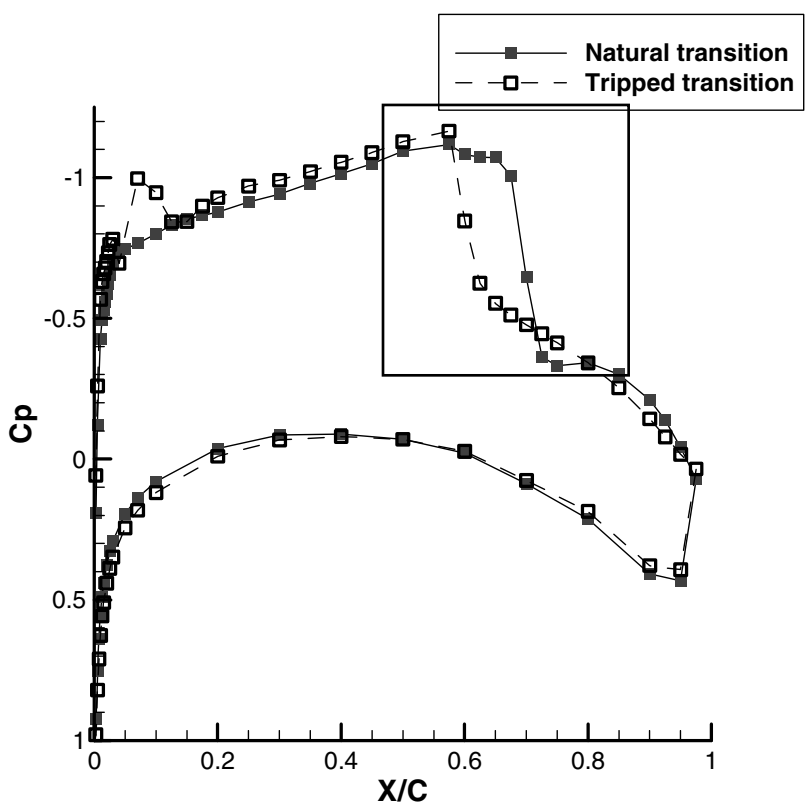

a) Pressure distributions

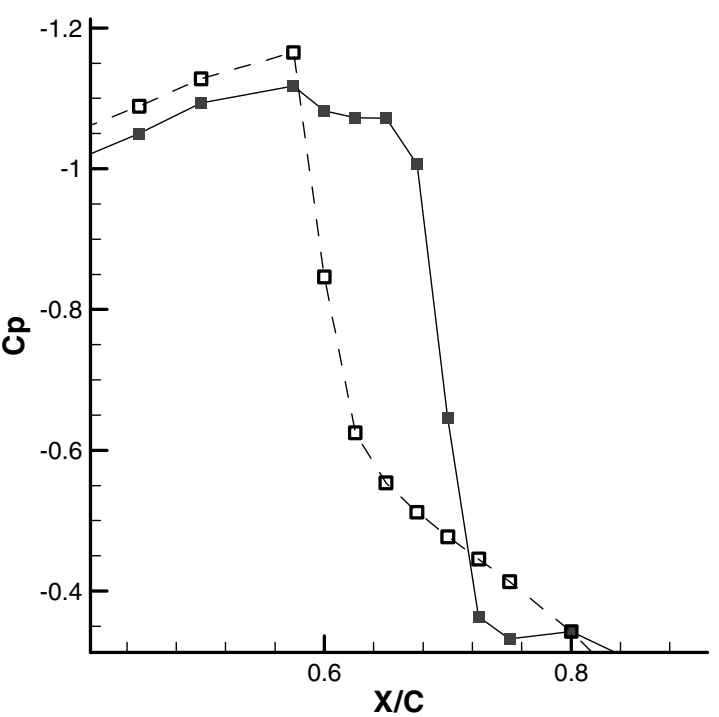

b) Shock area

Fig. 19 Experimental pressure distributions; $M=0.73, P_{i}=1.2 \mathrm{bar}, C_{L}=0.8$; natural and tripped transitions.

The experimental total drag values, obtained by the wake survey analyses, were systematically about $10-20 \%$ greater than the numerical drag from elsA in isolift conditions (even for turbulent cases). This point has been deeply investigated. The CFD results obtained by Dassault Aviation (unstructured solver and grids) are in good agreement with the elsA-ffd72 data. Nevertheless, the CFD studies that have been carried out do not model the whole wind-tunnel setup. One of the possible reasons for such differences in drag is a problem of acquisition or treatment with the wake rake data during the test campaign. As explained earlier, these data exhibited significant and unexpected oscillations. Anyway, to quantify the effects of laminar flow (natural vs triggered transition delta), both approaches are valid, and as it will be shown next, they exhibit satisfactory agreement. Second, as said in the section dedicated to the description of numerical methods, the drag breakdown obtained via the channel elsAffd72 is deeper than the one from the wake survey.

It is important to underline that, for the cases that have been chosen to highlight the laminar flow effects on aerodynamic coefficients, the transition location obtained via the elsA criteria is in satisfactory agreement with the experimental data. The conditions are the following: $M=0.70, R e=5.33$ million, $P_{i}=1.2$ bar, and $T_{i}=$ $295 \mathrm{~K}$. This Mach number has been preferred to a lower one because the laminar zone is more stable over the large range of lift coefficients that is investigated: $0.35<C_{L}<0.95$.

In Table 9, the natural transition locations predicted by the AHDGL criteria of elsA in the conditions detailed earlier are given in chord percentage. As can be noticed, the angle-of-attack increase is favorable to the pressure side laminar region expansion. On the other hand, at this Mach number, even if the $\alpha$ increase is not beneficial for the suction side, the laminar zone remains extended. As a consequence, the overall laminar extent considering the pressure and suction sides together exhibits a limited variation (transfer phenomenon). Concerning the computations for which the transition is triggered at $5 \%$ chord on the suction side, the transition locations predicted on the pressure side are equivalent to the ones shown in Table 9 .

Concerning the lift coefficient, the gain due to laminar airfoil property is made explicit in Fig. 20. In this figure, elsA computations with natural and triggered (5\% on suction side) transitions are compared. Both numerical and experimental deltas are given. The gain in $C_{L}$ can be estimated as close to 0.1 . This effect is constant over the range that has been studied. This beneficial impact of laminar flow on the lift produced by the airfoil is of prime importance in a perspective of aircraft design.
Concerning the drag coefficient, the equivalent comparison is shown in Fig. 21. A substantial reduction of total drag can be observed over the whole range of lift. It can be estimated to a $40-50 \%$ decrease. For instance, at $C_{L}$ close to 0.5 , the drag drop due to laminar airfoil design almost achieves 35 counts. This gain would be even larger with a $5 \%$ triggered transition on the pressure side also. The delta in drag is expressed both for numerical and wind-tunnel data. The experimental gain is extracted from Fig. 8. As can be noticed, the agreement between both approaches is quite satisfactory in terms of trends and values. The total drag reduction curves reach an optimum for $C_{L}$ close to 0.7 , before decreasing when the overall laminar region extent becomes more and more limited (see Table 9). To explain the sources of such a drag drop, far-field analyses have been performed.

The far-field extraction code ffd 72 has been applied on the numerical results shown in Fig. 21. The objectives were to identify the components responsible for this significant drag reduction and then to quantify the contributions of each one of them. The data obtained are presented in Fig. 22. As in this case, the wave drag coefficients exhibit values close to zero, and only the friction and viscous pressure drag components are given. The sum of these coefficients corresponds to the viscous drag (which is the total drag in the absence of $C_{D w}$ ). When observing Fig. 22, it can be observed that the evolution of $C_{D f}$ with natural transition rigorously follows the overall laminar region extent (last column of Table 9) and exhibits limited variation. Then, it appears that it is clearly not the friction coefficient alone that is responsible for the total drag reduction. Indeed, the viscous pressure drag component plays a major role in the drag drop due to laminar airfoil design. For lift coefficients close to 0.5 , the friction component shows a decrease, which represents $60 \%$ of the total drag reduction, whereas the viscous pressure drag is responsible for the remaining $40 \%$. At higher $C_{L}(0.85)$, the $C_{D v p}$

Table 9 Natural transition locations from elsA computations; $M=0.70, P_{i}=1.2 \mathrm{bar}, T_{i}=295 \mathrm{~K}$

\begin{tabular}{cccc}
\hline \hline$C_{L}$ & $\begin{array}{c}\text { Transition } \\
\text { pressure side, } \% c\end{array}$ & $\begin{array}{c}\text { Transition } \\
\text { suction side, } \% c\end{array}$ & $\begin{array}{c}\text { Overall } \\
\text { extent, } \% c\end{array}$ \\
\hline 0.39 & 41 & 76 & 117 \\
0.48 & 50 & 72 & 122 \\
0.70 & 64 & 62 & 126 \\
0.78 & 65 & 56 & 121 \\
0.94 & 68 & 50 & 118 \\
\hline \hline
\end{tabular}




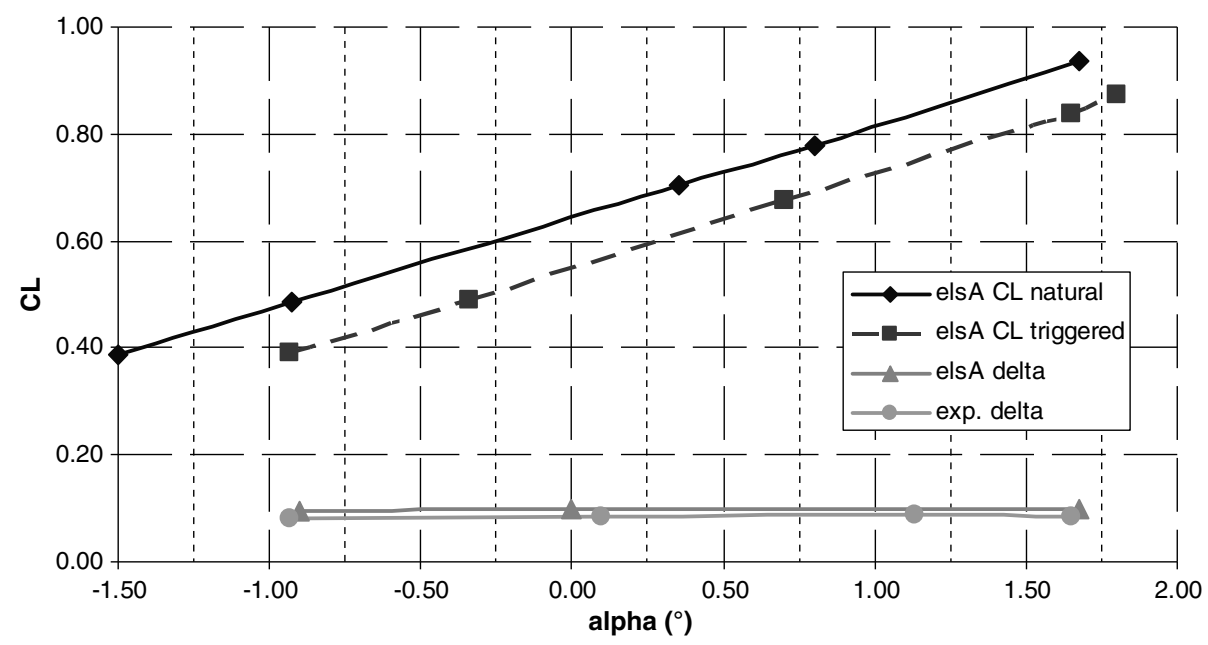

Fig. 20 Gain in $C_{L}$ coefficient due to laminar airfoil design; $M=0.70, P_{i}=1.2 \mathrm{bar}, T_{i}=295 \mathrm{~K}$.

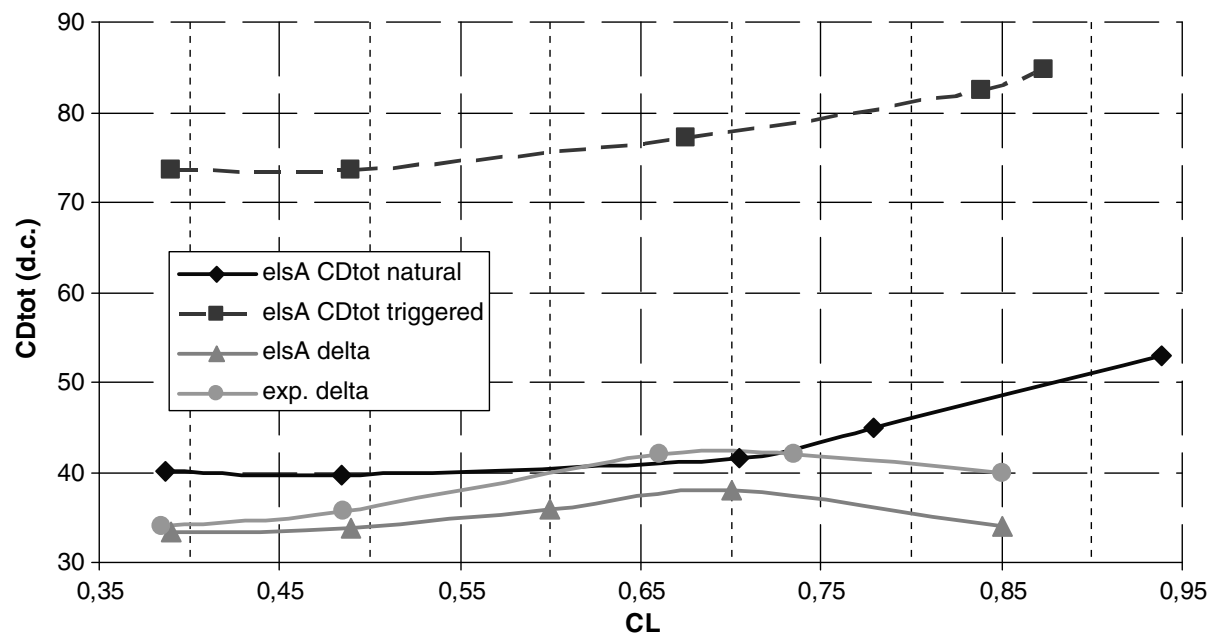

Fig. 21 Gain in $\mathrm{C}_{D}$ coefficient due to laminar airfoil design; $M=0.70, P_{i}=1.2 \mathrm{bar}, T_{i}=295 \mathrm{~K}$.

contribution is even stronger $(56 \%)$ than the one of the $C_{D f}$ component.

To continue with the far-field analysis in depth, the viscous pressure drag production along the chord has been plotted in Fig. 23 . Three curves are presented: two of them allow a natural vs triggered transition comparison at low lift level, whereas the third one represents a $C_{D v p}$ production with natural transition at high $C_{L}$. The figures reached by the production curves at the extreme right correspond to the ones that can be read in Fig. 22. Considering the $C_{D v p}$ production with natural transition at $C_{L}=0.39$, it can be seen that two slope breaks occur before the blunt trailing edge: the first one close to $40 \%$ chord and the second one at about $75 \%$. When comparing these values with the figures of Table $\underline{9}$, it clearly appears that the slope breaks in the viscous pressure drag production correspond to the transition locations. Indeed, in this case, the transition occurs at $41 \%$ chord on the pressure side and at $76 \%$ on the suction

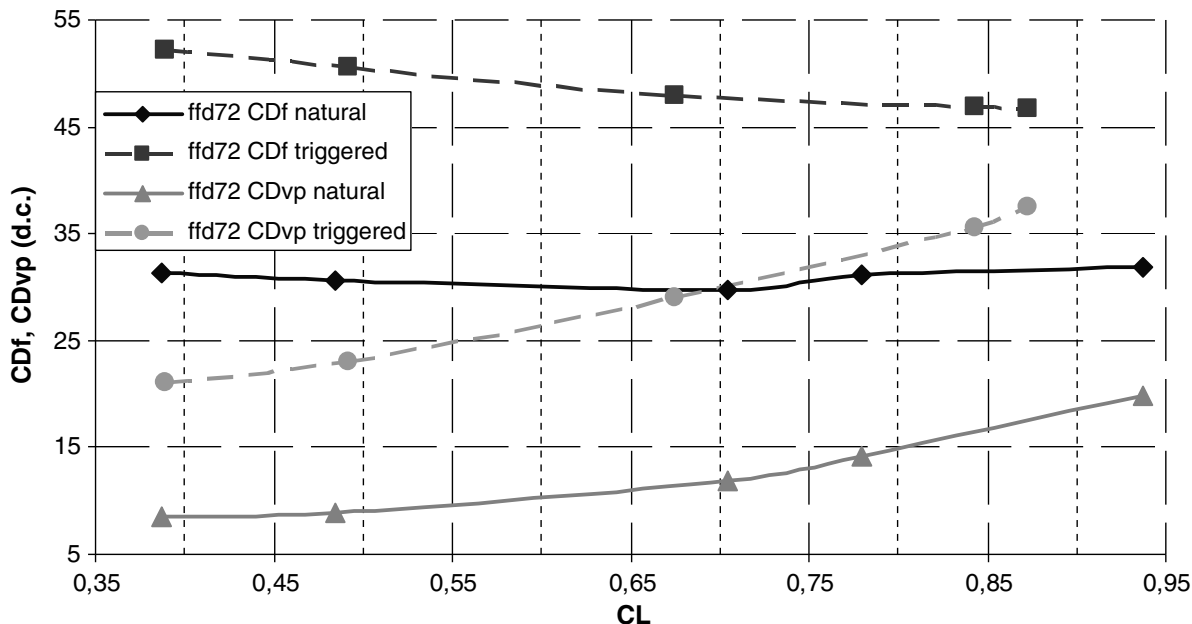

Fig. $22 C_{D f}$ and $C_{D v p}$ coefficients; natural vs triggered transition; $M=0.70, P_{i}=1.2 \mathrm{bar}, T_{i}=295 \mathrm{~K}$. 


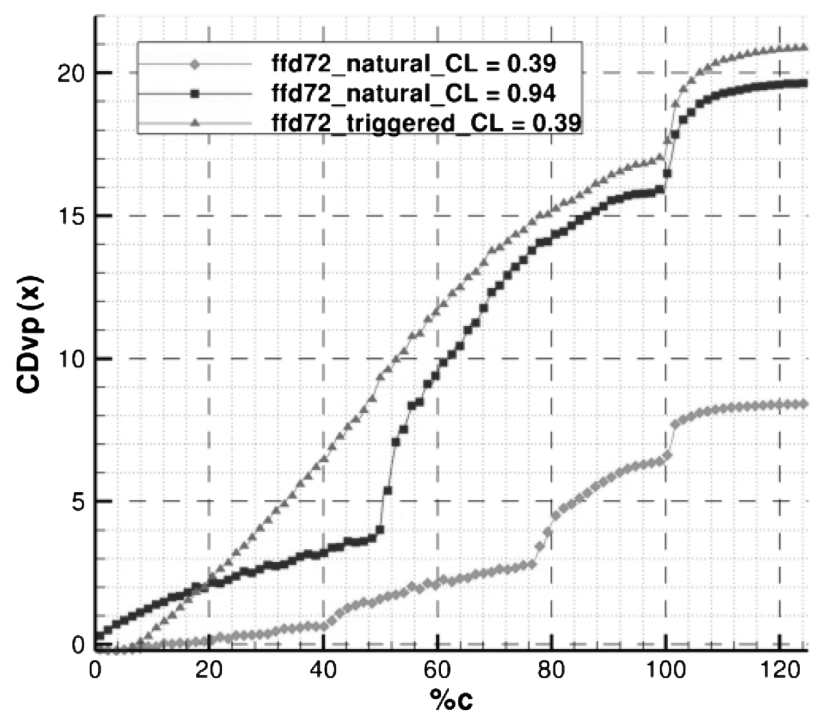

Fig. $23 C_{D v p}$ production along the chord; natural vs triggered transition; $M=0.70, P_{i}=1.2 \mathrm{bar}, T_{i}=295 \mathrm{~K}$.

side. It is therefore the boundary-layer status (laminar vs turbulent) that has a significant impact on the $C_{D v p}$ production rate. Concerning the curve showing the production for natural transition at a high $C_{L}$ of 0.94 , a major slope break is observed at $50 \%$ chord. In this case, it corresponds to the suction side transition location. The impact of the pressure side transition is less visible. Finally, it can be seen that, in the rear part of the airfoil (80-100\% chord), when all the boundary layers are turbulent, the curves of natural and triggered transitions exhibit similar $C_{D v p}$ production rates. At the end, the blunt trailingedge drag is visible at $100 \%$ chord (it is a classical feature of the farfield approach to record drag after the trailing edge).

\section{Parameter Effects on Transition Location and Drag}

In this section, some parameter effects on laminar/turbulent transition location and drag will be presented. First, an angle-ofattack sweep study at low Mach number will be shown. Then, the effects of Mach and Reynolds number variations will be presented. All the cases exhibit natural transition on both sides of the airfoil (no triggering).

\section{A. Angle-of-Attack Effects}

For the angle of attack sweep effects on transition location and drag, a low Mach has been chosen (i.e., conditions less favorable for the boundary-layer stability). The aerodynamic conditions are therefore the following: $M=0.66, R e=2.55$ million, $P_{i}=0.6 \mathrm{bar}$,
$T_{i}=297 \mathrm{~K}$. The angle of attack sweep presented in this paragraph leads to the lift coefficient range of $0.45<C_{L}<0.95$.

In Fig. 24, the effects of an angle-of-attack variation on the transition locations of both airfoil sides can be observed. Both numerical and experimental data are given, and they exhibit satisfactory agreement. It can be noticed that, despite the large range of angle of attack investigated, the transition location on the pressure side shows very limited variation. It moves from $60 \%$ chord for lowest incidences to $70 \%$ for highest ones. On the other hand, the suction side transition location exhibits a great displacement along the chord. This is due to the shock displacement. At low angles of attack, the laminar zone is very extended (up to $80 \%$ chord). This zone remains large (over 50\%) for lift coefficients up to about 0.75 , but then becomes very limited (from 25 to less than $15 \%$ ) for $C_{L}$ greater than 0.8 . This behavior was not observed in the cases with stronger Mach numbers (see Table 9).

The significant displacement of the transition location on the suction side has a clear impact on drag production. This effect is highlighted in Fig. 25, in which the laminar drag bucket phenomenon can be observed. In this case, due to the weak shocks (low Mach number), the wave drag is negligible. As a consequence, the total drag is the sum of the friction and viscous pressure coefficients. It can be seen that experimental total drag values are given for two points. As said previously, they are about $10-20 \%$ greater than the numerical drag. Nevertheless, both methods are in agreement in terms of trends. This figure should be compared with Fig. 22. At $M=0.66$ in Fig. 25, due to the substantial laminar region extent reduction on the suction side at high incidences, the increase of $C_{D f}$ and $C_{D v p}$ coefficients is much stronger. Furthermore, because the situation remains almost unchanged on the pressure side, it can be observed that the friction and viscous pressure drag curves precisely follow the inverse evolution of the suction side transition position. Finally, the similar behavior of $C_{D f}$ and $C_{D v p}$ coefficients underlines once again the importance of the viscous pressure component in the drag issues related to laminar/turbulent conditions (see Fig. 23).

\section{B. Mach Number Effects}

To highlight the beneficial effects of compressibility on laminar boundary-layer stability, a quite strong lift level has been chosen to compare the transition locations and drag productions at three different Mach numbers. The aerodynamic conditions are the following: $M=0.66,0.70$, and 0.73 , and $P_{i}=0.6$ bar. The computations have been realized in iso- $C_{L}$ conditions at a value of 0.79 .

For the three Mach numbers, the transition positions on both airfoil sides are given in Fig. 26. Experimental values are added; nevertheless, the lift coefficients of these wind-tunnel runs are not rigorously equal to 0.79 . Once again, it can be seen that the pressure side is almost unaffected: The location variation over the Mach number range does not exceed $5 \%$ chord. On the other hand, the

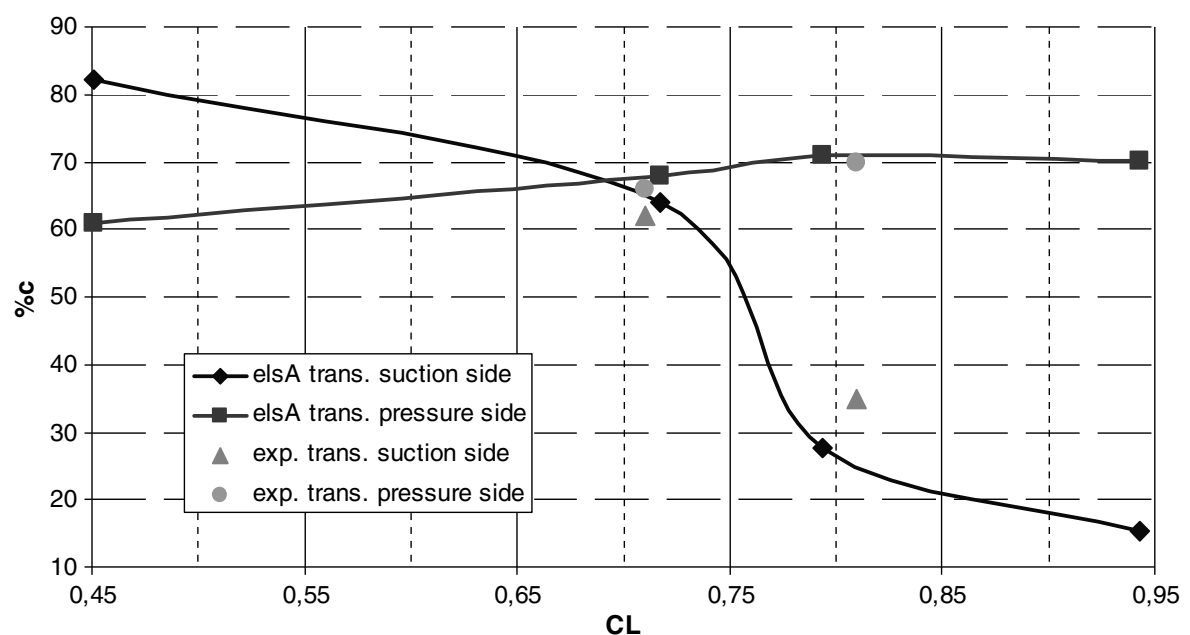

Fig. 24 Influence of angle of attack on transition location; $M=0.66, P_{i}=0.6 \mathrm{bar}, T_{i}=297 \mathrm{~K}$. 


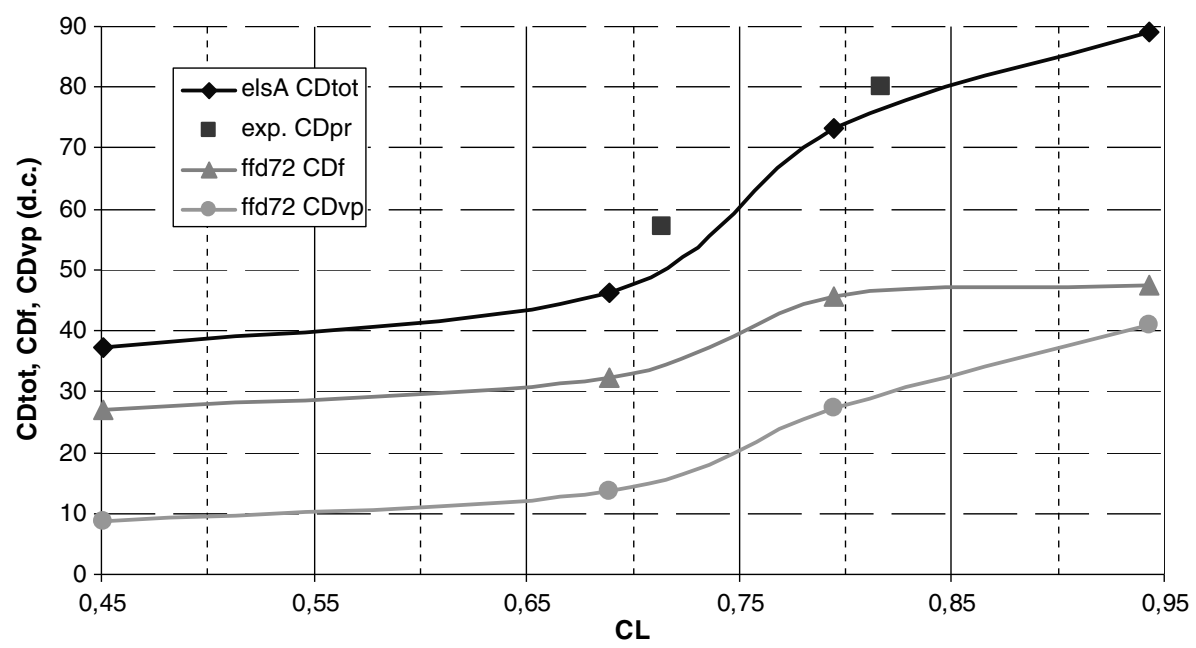

Fig. 25 Influence of angle of attack on drag components; $M=0.66, P_{i}=0.6 \mathrm{bar}, T_{i}=297 \mathrm{~K}$.

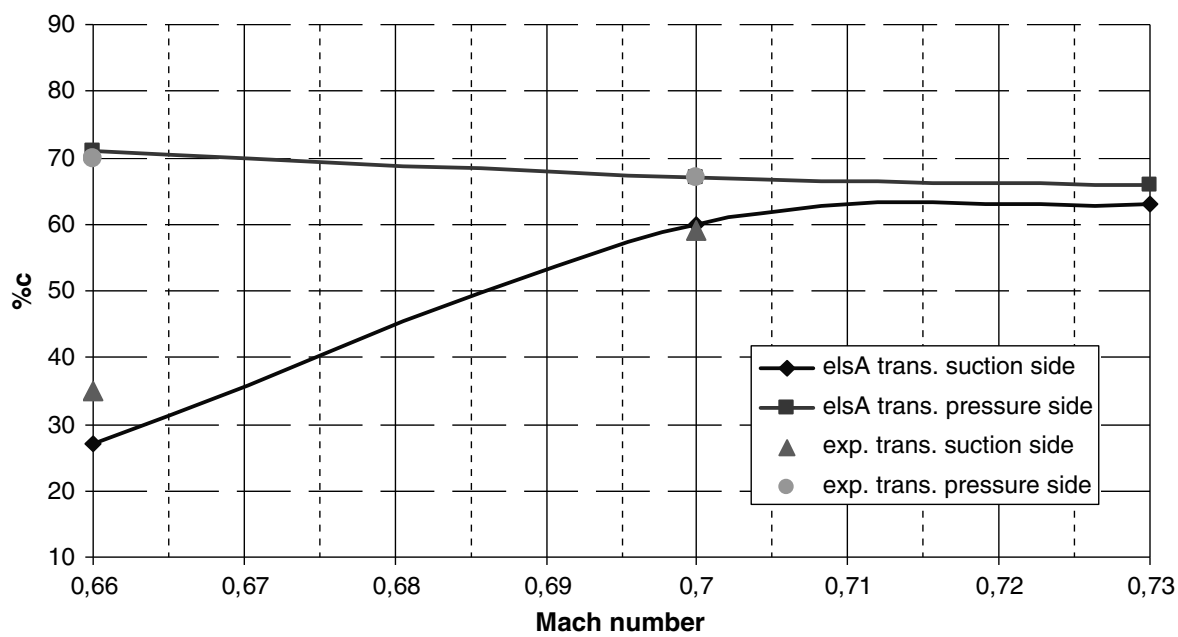

Fig. 26 Mach number effects, transition locations; $P_{i}=0.6$ bar, $C_{L}=0.79$.

transition location on the suction side dramatically changes when increasing the Mach number. At low speeds, the boundary layer becomes turbulent very early (the first point can also be seen in Fig. 24). However, when the Mach number reaches 0.7 , the boundary layer is more stable and remains laminar up to $60 \%$ chord and even further with a Mach number of 0.73. This illustrates the stabilizing effect of compressibility [33].
In Fig. 27, the evolution of the different drag components when increasing the Mach number can be observed. Here, the numerical total drag is the sum of the friction, viscous pressure, and wave components. Experimental values have been added. Even if there are discrepancies regarding absolute values, it can be noticed that the CFD and wind-tunnel trends are in agreement (especially concerning the wave drag coefficient). For both approaches, there is an optimum

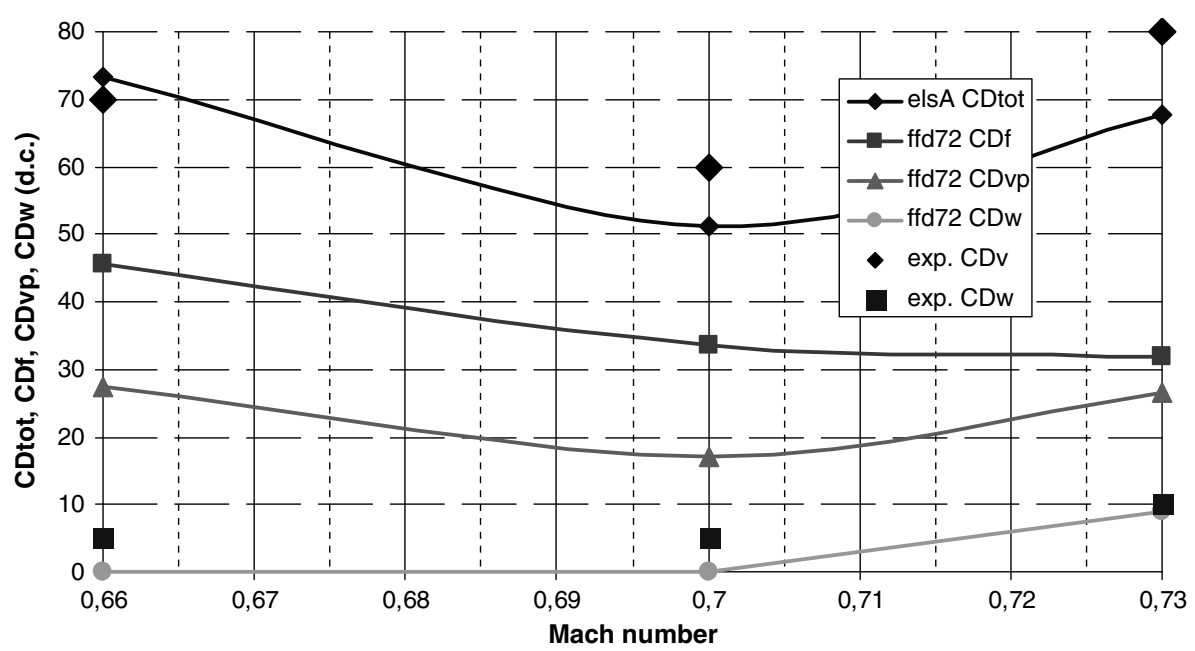

Fig. 27 Mach number effects, drag components; $P_{i}=0.6$ bar, $C_{L}=0.79$. 


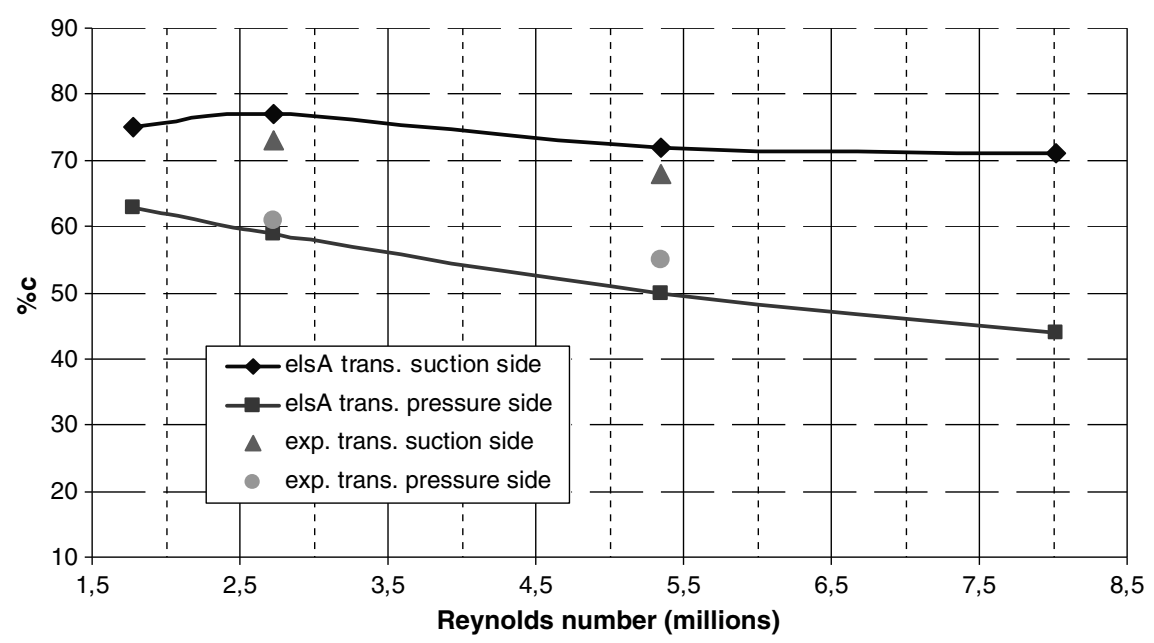

Fig. 28 Reynolds number effects, transition locations; $M=0.70, T_{i}=297 \mathrm{~K}, C_{L}=0.48$.

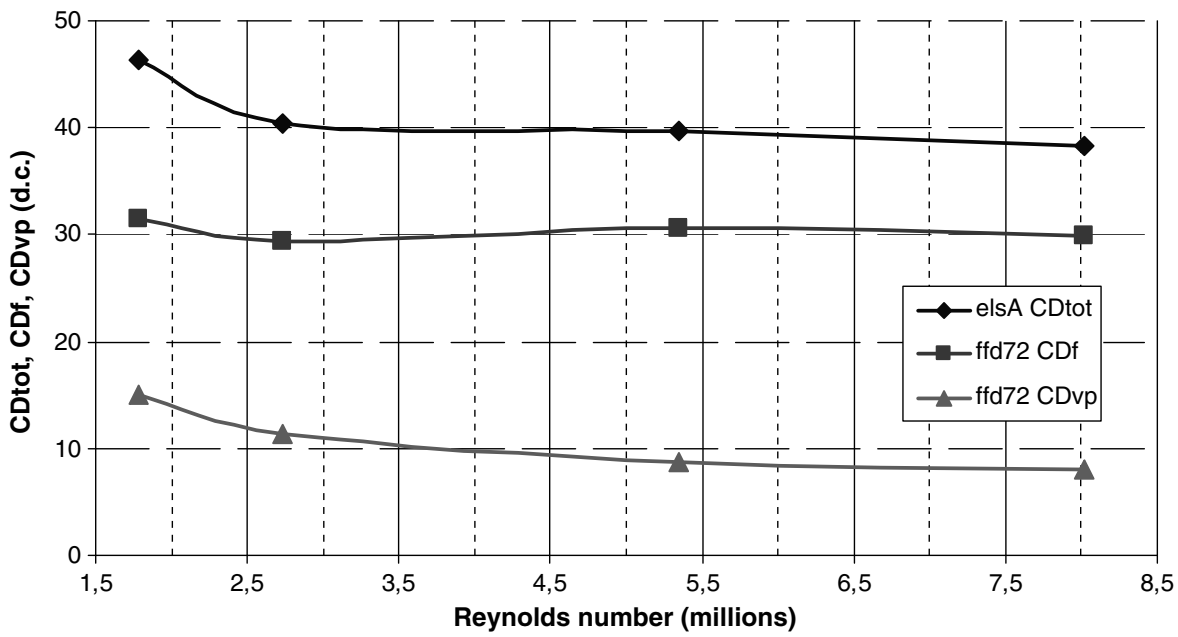

Fig. 29 Reynolds number effects, drag components; $M=0.70, T_{i}=297 \mathrm{~K}, C_{L}=0.48$.

in drag at Mach numbers close to 0.7. In these conditions, due to the laminar extent, the friction drag is low and the wave drag is still negligible. When the Mach number becomes stronger, the shock produces more and more wave drag and the viscous pressure drag is inevitably impacted. As a consequence, the total drag dramatically increases while the friction drag alone is still decreasing.

\section{Reynolds Number Effects}

Four Reynolds numbers from 1.8 to 8 million have been investigated. Intermediate Mach number and lift level have been chosen, respectively, as 0.70 and 0.48 . As a consequence, the conditions are the following: $M=0.70, P_{i}$ from 0.4 to $1.8 \mathrm{bar}$, and $T_{i}=297 \mathrm{~K}$. The computations have been performed in iso- $C_{L}$ conditions $C_{L}=0.48$.

The transition positions on both airfoil sides are given in Fig. 28 . The experimental values available for similar lift levels are also presented. It can be seen that the wind-tunnel and elsA trends are in agreement. They both indicate that increasing the Reynolds number while keeping the $C_{L}$ coefficient constant leads to transition locations closer to the leading edge. This is especially noticeable for the pressure side: The transition moves from about $63 \%$ chord to less than $45 \%$ when increasing the Reynolds number from 1.8 to 8 million. Indeed, added to the Reynolds number effect, another fact impacts the pressure side: With greater Reynolds numbers, the angle of attack needed to reach the specified $C_{L}$ is lower, which is not beneficial for the pressure side boundary-layer laminar expansion (see Fig. 24). The variation on the suction side is not straightforward to interpret, but its amplitude is quite limited (about 5\% chord) and its direction is confirmed by the experimental results.
Finally, the evolution of drag components due to Reynolds effects is shown in Fig. 29. As the wave drag is almost zero in these conditions, it is not represented. In this figure, it can be observed that the friction drag remains almost constant over the Reynolds number range. This is due to the opposition of two mechanisms. Classically, the friction drag coefficient decreases as the Reynolds number rises [32]. However, in this case, because the laminar area is less and less extended (see Fig. 28), the friction drag naturally tends to grow. It seems that both effects compensate each other. On the other hand, the viscous pressure drag exhibits the usual evolution due to the Reynolds number increase [32]. The thinning down of the boundary layers due to Reynolds effects is predominant and leads to a slight $C_{D v p}$ decrease.

\section{Conclusions}

This paper is focused on laminar-to-turbulent transition and drag predictions on two-dimensional laminar airfoils. Various experimental and CFD approaches have been employed. A test campaign was carried out in 2012 in the S2MA ONERA wind-tunnel and included flow quality measurements and static pressure probing, as well as infrared imaging and wake survey, providing substantial data in transonic conditions. The flow conditions corresponded to Mach numbers ranging between 0.66 and 0.73 and stagnation pressures between 0.6 and 1.8 bar $(1.4<R e<8.6$ million). A large range of lift coefficients has been investigated. Furthermore, to quantify the influence of laminar flow on the airfoil performance, such as lift and drag coefficients, the laminar/turbulent transition could be fully natural or triggered at $5 \%$ chord. 
Concerning experimental drag evaluations, the rake located downstream of the airfoil has allowed a drag breakdown into viscous and wave drag coefficients using a proper orthogonal decomposition on a family of reference profiles. Unfortunately, due to some oscillations in the probing signal, experimental data had to be smoothed and this led to a nonnegligible uncertainty of measurement. Nevertheless, the drag reduction due to laminar design has been quantified, as well as the evolution of drag components for consequent ranges of Mach and Reynolds numbers and angle of attack.

In complement of these measurements, a whole CFD restitution study has been undertaken. The objective of such analyses was twofold. The first purpose was to validate the current numerical tools developed and used in ONERA. The second objective was to allow a deeper understanding of physical phenomena. The transition process has been studied by two different methods. First, exact stability computations have been performed. They have provided for each Tollmien-Schlichting wave an amplification rate, which is quantified through a so-called $N$ factor. This approach is powerful but requires solving an eigenvalue problem. The second method is based on a combination of the Arnal-Habiballah-Delcourt and Gleyzes transition criteria, which have been directly introduced in the elsA NavierStokes solver. These RANS computations have been performed on a two-dimensional structured grid with $\mathrm{C}$ topology adapted to accurately compute boundary layers as well as the wake area. Finally, to have access to drag components, the solver solutions have been analyzed with a far-field extraction code, which enables splitting of the total drag into friction, viscous pressure, and wave components.

Regarding the results, for almost all the cases, numerical pressure distributions were in good agreement with the experimental data, and in such conditions, the elsA approach based on the AHD-GL transition criteria has provided an accurate transition location in comparison with the stability analyses and infrared imaging. Nevertheless, the RANS solver was unable to properly simulate the long separation bubble resulting from the laminar boundary-layer/shock interaction. This point is a current challenge to address to improve RANS computation efficiency. It would require the capture of transition mechanisms inside the bubble but also accurate modeling of the transition region through a dedicated intermittency function.

Considering the gains due to laminar design, the numerical farfield approach has been particularly used to compare natural and triggered transitions. In equivalent lift conditions, the laminar flow can lead to substantial drag decreases of $40-50 \%$, and the contribution of the viscous pressure drag in this gain is almost equivalent to the friction drag reduction.

Finally, influences of angle of attack and Mach and Reynolds numbers on transition and drag production have been quantified, and the optimal Mach number regarding drag coefficient has been identified.

This work was a major step toward accurate and automatic transition prediction in RANS solvers, including drag analysis for twodimensional configurations. In the near future, these numerical tools will be more and more employed with the development of new laminar airfoils. The next step will consist of performing such an analysis for a representative 3-D configuration. In these conditions, Tollmien-Schlichting waves are in competition with crossflow instabilities. Unfortunately, at that time, prediction criteria for crossflowinduced transition are extracted from experimental correlations based on limited test cases. An interesting solution could be the use of database methods (including transversal disturbances) directly integrated in the RANS solver. In 2014 and 2015, new numerical and experimental studies are in progress at ONERA to apply, extend, and validate the methods of this paper to a complex 3-D aircraft configuration. The outcomes obtained from these current investigations will be addressed in a future article.

\section{Acknowledgments}

This work has been undertaken within the Joint Technology Initiative "JTI CleanSky," Smart Fixed Wing Aircraft Integrated Technology Demonstrator project (contract CSJU-GAM-SFWA2008-001) financed by the Seventh Framework Programme of the
European Commission. The authors would like to thank their Dassault Aviation colleagues G. Petit, V. Woizard, D. Tran, B. Plantin, J. C. Courty, and P. Rostand for their active participation in the preparation and realization of the experimental campaign. The authors would also like to warmly thank their ONERA colleagues I. Salah el Din, J. Mayeur, J. Perraud, H. Deniau, and E. Coustols for their help and fruitful conversations. Special thanks are given to the ONERA S2MA wind-tunnel team who prepared the models and realized the measurements.

\section{References}

[1] Joslin, R. D., "Overview of the Laminar Flow Control," NASA TP1998-208705, 1998, http://ntrs.nasa.gov/archive/nasa/casi.ntrs.nasa gov/19980232017.pdf.

[2] Somers, D. M., "Subsonic Natural-Laminar Flow Airfoils," Natural Laminar Flow and Laminar Flow Control, edited by Barnwell, R. W., and Hussaini, M. Y., Springer-Verlag, New York, 1992, pp. 143-176. doi:10.1007/978-1-4612-2872-1

[3] Amoignon, O., Pralits, J., Hanifi, A., Berggen, M., and Henningson, D., "Shape Optimization for Delay of Laminar-Turbulent Transition," AIAA Journal, Vol. 44, No. 5, 2006, pp. 1009-1024. doi: $10.2514 / 1.12431$

[4] Viken, J. K., Viken, S. A., Pfenninger, W., Morgan, H. L., Jr., and Campbell, R. L., "Design of the Low Speed NLF (1)-0414F and the High-Speed HSNLF(1)-0213 Airfoils with High Lift Systems," Research in Natural Laminar Flow and Laminar Flow Control, NASA CP-2487, 1987, pp. 637-671, http://ntrs.nasa.gov/archive/nasa/casi.ntrs .nasa.gov/19900003224.pdf.

[5] Sewall, W. G., McGhee, R. J., Hahne, D. E., and Jordan, F. L., Jr., "Wind Tunnel Results of the High-Speed NLF(1)-0213 Airfoil," Research in Natural Laminar Flow and Laminar Flow Control, NASA CP-2487, Pt. 3, 1987, pp. 697-726, http://ntrs.nasa.gov/archive/nasa/casi.ntrs .nasa.gov/19900003226.pdf.

[6] Sewall, W. G., McGhee, R. J., Viken, J. K., Waggoner, E. G., Walker, B. S., and Millard, B. F., "Wind Tunnel Results for a High-Speed, Natural Laminar-Flow Airfoil Designed for General Aviation Aircraft," NASA TM-87602, 1985, http://ntrs.nasa.gov/archive/nasa/casi.ntrs.nasa.gov/ 19880004696.pdf.

[7] Fujino, M., Yoshizaki, Y., and Kawamura, Y., "Natural-Laminar-Flow Airfoil Development for a Lightweight Business Jet," Journal of Aircraft, Vol. 40, No. 4, 2003, pp. 609-615. doi: $10.2514 / 2.3145$

[8] Perraud, J., Salah El Din, I., Schrauf, G., Hanifi, A., Donelli, R., Hein, S., Fey, U., Egami, Y., and Streit, T., "High Reynolds Number Transition Experiments in the ETW Test Facility with the Pathfinder Model," 5th European Conference on Computational Fluid Dynamics, ECCOMAS Paper 01788, June 2010.

[9] Streit, T., Horstmann, K. H., Schrauf, G., Hein, S., Fey, U., Egami, Y., Perraud, J., Salah El Din, I., Cella, U., and Quest, J., "Complementary Numerical and Experimental Data Analysis of the ETW Telfona Pathfinder Wing Transition Tests," 49th Aerospace Sciences Meeting, AIAA Paper 2011-0881, Jan. 2011. doi: $10.2514 / 6.2011-881$

[10] Mack, L. M., "Transition Prediction and Linear Stability Theory," AGARD Conference Proceedings, NATO, Paris, No. 224, 1977, pp. 122.

[11] Betz, A., "Ein Verfahren zur direkten Ermittlung des Profilwiderstandes," Zeitschrift fur Flugtechnik und Motorluftschifahrt (ZFM), Vol. 16, 1925, pp. 42-44.

[12] Jones, B., "Measurement of Profile Drag by the Pitot-Traverse Method," British Aeronautical Research Council Rept. 1688, London, 1936.

[13] Oswatitsch, K., "Gas Dynamics," Academic Press, New York, 1956.

[14] Maskell, E. C., "Progress Towards a Method for the Measurement of the Components of the Drag of a Wing of Finite Span," Royal Aircraft Establishment TR-72232, London, 1972.

[15] Brune, G. W., "Quantitative Low-Speed Wake Surveys," Journal of Aircraft, Vol. 31, No. 2, 1994, pp. 249-255. doi: $10.2514 / 3.46481$

[16] Kusunose, K., "Development of a Universal Wake Survey Data Analysis Code," 15th Applied Aerodynamics Conference, AIAA Paper 1997-2294, June 1997. doi: $10.2514 / 6.1997-2294$

[17] Kusunose, K., Crowder, J. P., and Watzlavick, R. L., "Wave Drag Extraction from Profile Drag Based on a Wake-Integral Method," 37th AIAA Aerospace Sciences Meeting and Exhibit, AIAA Paper 19990275, Jan. 1999 doi: $10.2514 / 6.1999-275$ 
[18] Kusunose, K., and Crowder, J. P., "Extension of Wake Survey Analysis Method to Cover Compressible Flows," Journal of Aircraft, Vol. 39, No. 6, 2002, pp. 954-963. doi: $10.2514 / 2.3048$

[19] Méheut, M., and Bailly, D., "Drag Breakdown Methods from Wake Measurements," AIAA Journal, Vol. 46, No. 4, 2008, pp. 847-862. doi:10.2514/1.29051

[20] Perraud, J., Vermeersch, O., and Houdeville, R., "Descriptif et mode d'emploi du code 3C3D," ONERA TR-1/18325-DMAE, ONERA, Palaiseau, France, 2011.

[21] Arnal, D., Habiballah, M., and Coustols, E., "Laminar Instability Theory and Transition Criteria in Two and Three-Dimensional Flow," La Recherche Aerospatiale, No. 2, 1984, pp. 45-63 (in English).

[22] Cliquet, J., Houdeville, R., and Arnal, D., "Application of LaminarTurbulent Transition Criteria in Navier-Stokes Computations," AIAA Journal, Vol. 46, No. 5, 2008, pp. 1182-1190. doi: $10.2514 / 1.30215$

[23] Arnal, D., Houdeville, R., Séraudie, A., and Vermeersch, O., "Overview of Laminar-Turbulent Transition Investigations at ONERA Toulouse," 41 st AIAA Fluid Dynamics Conference and Exhibit, AIAA Paper 20113074, June 2011 doi: 10.2514/6.2011-3074

[24] Gleyzes, C., Cousteix, J., and Bonnet, J. L., "Theoretical and Experimental Study of Low Reynolds Number Transitional Separation Bubbles," Conference on Low Reynolds Number Airfoil Aerodynamics, 1985.

[25] Cambier, L., Heib, S., and Plot, S., "ONERA elsA CFD Software: Input from Research and Feedback from Industry," Mechanics and Industry, Vol. 14, No. 3, 2013, pp. 159-174.

[26] Cambier, L., and Gazaix, M., "elsA: An Efficient Object-Oriented Solution to CFD Complexity," 40th AIAA Aerospace Sciences Meeting and Exhibit, AIAA Paper 2002-0108, Jan. 2002. doi: $10.2514 / 6.2002-108$
[27] Jameson, A., Schmidt, W., and Turkel, E., "Numerical Solution of the Euler Equations by Finite Volume Methods Using Runge Kutta Time Stepping Schemes," 14th Fluid and Plasma Dynamics Conference, AIAA Paper 1981-1259, June 1981. doi:10.2514/6.1981-1259

[28] Spalart, P. R., and Allmaras, S. R., "One-Equation Turbulence Model for Aerodynamic Flows," 30th Aerospace Sciences Meeting and Exhibit, AIAA Paper 1992-0439, Jan. 1992 doi:10.2514/6.1992-439

[29] Destarac, D., "Spurious Far-Field-Boundary Induced Drag in TwoDimensional Flow Simulations," Journal of Aircraft, Vol. 48, No. 4 July-Aug. 2011, pp. 1444-1455. doi:10.2514/1.C031331

[30] Destarac, D., "Far-Field/Near-Field Drag Balance Applications of Drag Extraction in CFD," CFD-Based Aircraft Drag Prediction and Reduction, VKI Lecture Series 2003-02, von Kármán Inst. for Fluid Dynamics, Rhode-Saint-Genèse, Belgium, Nov. 2003.

[31] Van der Vooren, J., and Destarac, D., "Drag/Thrust Analysis of JetPropelled Transonic Transport Aircraft; Definition of Physical Drag Components," Aerospace Science and Technology, Vol. 8, No. 6, Sept. 2004, pp. 545-556.

[32] Hue, D., and Esquieu, S., "Computational Drag Prediction of the DPW4 Configuration Using the Far-Field Approach," Journal of Aircraft, Vol. 48, No. 5, 2011, pp. 1658-1670. doi:10.2514/1.C031337

[33] Arnal, D., and Vermeersch, O., "Compressibility Effects on LaminarTurbulent Boundary Layer Transition," International Journal of Engineering Systems Modelling and Simulation, Vol. 3, Nos. 1-2, 2011, pp. 26-35.

G. Blaisdell Associate Editor 